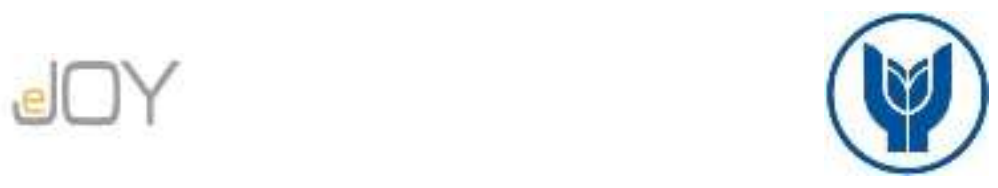

Eyüboğlu, K., Eyüboğlu, S. / Journal of Yasar University, 2020, 15/59, 642-654

\title{
Borsa İstanbul Endekslerinde Adaptif Piyasa Hipotezinin Geçerliliğinin Test Edilmesi ${ }^{1}$
}

Testing the Validity of Adaptive Market Hypothesis in Borsa Istanbul Indices

\author{
Kemal EYÜBOĞLU, Tarsus Üniversitesi, Türkiye, keyuboglu@msn.com \\ Orcid No: 0000-0002-2108-9732 \\ Sinem EYÜBOĞLU, Tarsus Üniversitesi, Türkiye, sinemeyuboglu@ tarsus.edu.tr \\ Orcid No: 0000-0002-3525-9173
}

\begin{abstract}
Öz: Bu çalışmada Borsa İstanbul endekslerinde (BIST 100, Sinai ve Mali) Adaptif Piyasa Hipotezinin geçerli olup olmadığı günlük veriler kullanılarak incelenmiştir. Veri aralığı BIST 100 için 02 Ocak 1990-17 Haziran 2019; BIST Sinai ve Mali için 02 Nisan 1991-17 Haziran 2019'dur. Çalışmada günlük getiri verileri, iki yılllk alt örneklere ayrllmış ve hisse senedi getirilerinin öngörülebilirliğinin zaman içinde nasıl değiştiğini belirlemek için doğrusal ve doğrusal olmayan testler uygulanmiştır. Otokorelasyon ve runs testlerinden elde edilen sonuçlar, genellikle 3 endeksin etkin ve etkin olmayan dönemler arasında geçiş yaptığını ve dolayısıyla piyasaların Adaptif Piyasa Hipotezi ile uyumlu olduğunu ortaya koymuştur. Varyans oranı testi ile doğrusal olmayan testlerin sonuçları ise hisse senedi getirilerinin tahmin edilebilir olduğunu dolayısıyla piyasaların etkin olmadığın göstermiştir.
\end{abstract}

Anahtar Sözcükler: Adaptif Piyasa Hipotezi, Doğrusal Testler, Doğrusal Olmayan Testler, Borsa İstanbul JEL Siniflandirmasl: D53, G11, G14

\begin{abstract}
In this study, whether the Adaptive Market Hypothesis is valid in Borsa Istanbul indices (BIST 100, Industrial and Financial) is examined by using daily data. Data range for BIST 100 is 02 January 1990-17 June 2019 and 02 April 1991-17 June 2019 for BIST Industrial and Financial.Daily return data are divided into two-year subsamples and linear and nonlinear tests are applied to determine how the stock returns' independence changed over time. Autocorrelation and runs test results show that the efficiency of each market varied within the sub-periods and therefore the markets are consistent with the Adaptive Market Hypothesis. The results of the variance ratio test and nonlinear tests show that stock returns are predictable and therefore the markets are inefficient.
\end{abstract}

Keywords: Adaptive Market Hypothesis, Linear Tests, Nonlinear Tests, Borsa Istanbul

JEL Classification: D53, G11, G14

\section{Giriş}

Fama (1970) tarafından geliştirilen Etkin Piyasa Hipotezi (EPH), son 40 yılda finans alanındaki en önemli ve geçerliliği en çok araştırılan teorilerden biri olmuştur. Etkin piyasa hipotezine göre tüm bilgiler tamamen ve anında piyasadaki fiyatlara yansıdığında piyasa etkin kabul edilmektedir. Bu tür piyasalarda piyasa katılımcılarının hiçbiri aşırı bir getiri elde edememektedir. Fama (1970) zayıf formda etkinlik, yarı güçlü formda etkinlik ve güçlü formda etkinlik olmak üzere üç çeşit etkinlik tanımlamıştır. Zayıf formda etkinlikte geçmişteki tüm bilgilerin, yarı güçlü formda etkinlikte halka açık tüm bilgilerin fiyatlara yansıdığı varsayılır. Güçlü formda etkinlikte ise hisse senedi fiyatlarının kamuya duyurulmuş ve duyurulmamış tüm bilgileri yansıttığı kabul edilir. Mevcut literatürdeki çalışmalarda borsaların etkin olduğu konusunda genel bir uzlaşma sağlanamamıştır. Zayıf formda etkinlik ise, finans literatüründe EPH'nin en çok test edilen şeklidir. Zayıf formda etkin bir piyasada, geçmişteki fiyat hareketleri ile gelecekteki fiyatları tahmin etmek imkansızdır. Bununla birlikte, irrasyonel yatırımcı davranışlarını araştıran bazı çalışmalar (aşırı tepki ve aşııı güvenirlik gibi) bu konuda farklı bir değerlendirmeye sahiptir (DeBondt ve Thaler, 1985; Barber ve Ordean, 2001). Zayıf formda etkinliği inceleyen çalışmaların birçoğunda piyasanın etkinliği tüm dönem boyunca ya etkin ya da etkin değil şeklinde yorumlanmıştır. Bu, piyasa etkinliğinin tüm dönem boyunca ya hep var olduğu, ya da hiç olmadığı anlamına gelmektedir. Bununla birlikte, pek çok piyasa faktörü nedeniyle (kurumsal, düzenleyici ve teknolojik değişiklikler, piyasa katılımcılarının demografik davranışları gibi) piyasa etkinliğinin zaman içinde değişkenlik göstermesini beklemek daha makul olacaktır (Urquhart ve Hudson, 2013: 130). Lo (2004, 2005) literatürdeki çalı̧̧maların piyasa etkinliği konusundaki eksikliğini gidermek amaciyla alternatif bir teori olan Adaptif Piyasa Hipotezini (APH) geliştirmiştir.

APH, EPH'yi sınırlı rasyonellik kavramına uyarlamak için bir çerçeve sunmaktadır. APH'nin temeli, değisşen piyasa koşullarına (örneğin, balonlar, iflaslar ve krizler) ve kurumsal faktörlere bağlı olarak zaman zaman değişebilen piyasanın etkinliği ile ilgilidir. Bu teori piyasaların olaylar ve yapısal değişiklikler nedeniyle etkinliğinin değişebildiğini iddia etmektedir. Özetle, teori piyasanın etkinliğinin zaman içerisinde değişebileceğini öne sürmektedir (Lo, 2005). Bunun

${ }^{1} \mathrm{Bu}$ çalışma, 23. Finans Sempozyumunda sunulan bildirinin gözden geçirilmiş ve genişletilmiş halidir.

Makale Gecmiși / Article History

Başvuru Tarihi / Date of Application

: 15 Ekim / October 2019

Kabul Tarihi / Acceptance Date

: 13 Şubat / February 2020

(C) 2020 Journal of Yaşar University. Published by Yaşar University. Journal of Yaşar University is an open access journal.

There is no conflict of interest or ethical concern regarding this publication. 
nedeni kurumlar, düzenlemeler ve teknolojik değişiklikler ve piyasa katılımcılarının davranışları gibi değişen temel piyasa faktörleridir (Ghazani ve Araghi, 2014: 51). Aynı şekilde Lim ve Brooks (2011) yatırımcıların kendi çıkarları doğrultusunda hareket etmesini, hata yapmalarını, öğrenip adapte olmalarını, rekabetin uyarlama ve yeniliği teşvik etmesini APH'yi ortaya çıkaran kavramlar olarak tanımlamıştır. EPH'nin aksine, APH piyasaların uyarlanabilir olduğunu, zaman içinde geliştiğini ve dolayısıyla farklı zamanlarda etkinlik ve etkinsizlik arasında geçiş yaptığını savunmaktadır. Başka bir deyişle, bir borsanın etkinliği statik değil, zamanla değişkendir (Hiremath ve Narayan, 2016: 173). APH'ye göre;

- Risk primi, piyasa koşullarına ve bu koşullardaki yatırımcıların demografik özelliklerine göre zaman içinde değişmektedir.

- EPH'nin tersine arbitraj firsatı zaman zaman oluşmaktadır.

- Piyasanın koşullarına bağlı olarak yatırım stratejilerinin başarısı zaman zaman artıp zaman zaman azabilmektedir.

- Piyasalarda ayakta kalabilmek için yenilik en önemli faktördür. Piyasadaki değişen durumlara ayak uydurularak belirli bir düzeyde getiri elde edilebilir.

- $\quad$ Bütün piyasa katılımcılarının öncelikli hedefleri hayatta kalmaktır (Ertaş ve Özkan, 2018: 28-29).

$\mathrm{Bu}$ çalışmanın amacı, Borsa İstanbul endekslerinde fiyat oluşumlarının APH ile uyumlu olup olmadığını değerlendirmektir. Çalışmanın birkaç yönüyle literatüre katkı sağlayacağı tahmin edilmektedir. Birincisi yazarların bildiği kadarıyla Borsa İstanbul'da APH'nin geçerliliğini inceleyen tek bir çalışma (Ertaş ve Özkan, 2018) bulunmaktadır ve çalışmada sadece BIST 100 endeksinde APH'nin geçerliliği araştırılmıştır. Dolayısıyla bu çalışma sektör endekslerinde APH'nin geçerliliğini araştıran ilk çalışmadır. İkincisi, bu çalışmada çeşitli doğrusal ve doğrusal olmayan testler kullanılarak analizlerin güvenirliği arttırılmıştır. Böylece hisse senedi getirilerinin ana dinamikleri çok boyutlu olarak ortaya koyulmuştur. Üçüncüsü, bu çalışmada endeks verileri (veri aralığı XU100 için 02 Ocak 1990-17 Haziran 2019; XUSIN ve XUMAL için 02 Nisan 1991-17 Haziran 2019) alt dönemlere ayrılarak incelenmiştir.

Çalışmanın bundan sonraki bölümlerinde menkul kıymet piyasalarında APH'nin geçerliliğini inceleyen çalışmalar özetlenecektir. Üçüncü bölümde ise çalışmada kullanılan veri seti ve yöntem tanıtılacaktır. Çalışmanın son bölümünde ise yapılan analizler sonucu elde edilen bulgular sunulacaktır.

\section{Literatür Taraması}

Lim ve Brooks (2006), 23 gelişmiş ve 27 gelişmekte olan ülkede piyasaların etkinliğinin zaman içindeki değişimlerini Hinich (1996) portmanteau çift korelasyon testi ile incelemişlerdir. Farklı dönemlerin ele alındığı çalışmada piyasa etkinliğinin döngüsel bir biçimde zaman içinde değiştiğini ifade etmişlerdir.Todea vd. (2009) 1997-2008 dönemi için altı Asya sermaye piyasasının (Avustralya, Hong Kong, Hindistan, Malezya, Singapur ve Japonya) etkinliğini Hinich (1996) portmanteau çift korelasyon testi ile araştırmışlardır. Sonuçlar, APH ile uyumlu bir şekilde piyasa etkinliğinin zaman içerisinde döngüsel bir biçimde değiştiği göstermiştir. Ito ve Sugiyama (2009) 1955-2006 dönemi için aylık S\&P500 getirilerinin zamanla değişen otokorelasyonunu ele almışlardır. Elde edilen sonuçlar piyasa etkinliğinin zamanla değiştiğini, 1980'lerin sonunda piyasanın en az etkin seviyede, 2000'li y1llarda en etkin seviyede olduğunu göstermiştir.

Kim vd. (2011) 1900-2009 dönemi için hem günlük hem de haftalık veriler kullanarak DJIA endeksinde APH'nin geçerliliğini araştırmışlardır. Çalışmada otokorelasyon testleri (varyans oranı ve portmanteau) ve genelleştirilmiş spektral test kullanılmıştır. Yapılan analizler sonucunda getiri tahmin edilebilirliğinin zaman içinde Lo (2004) tarafından tarif edilene benzer şekilde dalgalanma gösterdiği ve piyasanın 1980'den sonra daha etkin hale geldiği belirlenmiştir. Smith (2012) Şubat 2000-Aralık 2009 dönemini kapsayan çalışmasında Yunanistan, Portekiz ve İngiltere piyasalarının yanı sıra, Avrupa'da on beş piyasada daha APH'nin geçerliliğini test etmiştir. Varyans oranı testleri yardımıyla en etkin piyasaların Türkiye, İngiltere Macaristan ve Polonya piyasaları olduğu, en az etkin olanların ise Ukrayna, Malta ve Estonya olduğu belirlenmiştir. Ayrıca on sekiz piyasanın her birinin ADH ile tutarlı olduğu saptanmıştır. Lim vd. (2013) 31 Aralık 1969 - 31 Aralık 2008 dönemini kapsayan çalışmalarında otomatik portmanteau Box-Pierce testi ve bootstrapped otomatik varyans oranı testi kullanılarak üç ABD hisse senedi endeksinde (DJIA, S\&P 500 ve NYSE Composite) getirilerin önceden tahmin edilebilip edilemeyeceğini analiz etmişlerdir. Yapılan analizler sonucunda getiri tahmin edilebilmesinin zaman içerisinde sabit kalmayıp değiştiğini ve dolayısıyla sonuçların APH ile örtüştüğünü ifade etmişleridir. Popović vd. (2013) 2004-2011 dönemi için Karabağ hisse senedi piyasasını temsil eden MONEX20 endeksinde getirilerin önceden tahmin edilip edilemeyeceğini incelemişlerdir. Yapılan haddeleme analizleri piyasada APH'nin geçerli olduğunu göstermiştir.

Urquhart ve Hudson (2013) APH'nin geçerliliğini üç piyasa (ABD, İngiltere ve Japonya) için incelemişlerdir. Doğrusal (otokorelasyon, runs ve varyans oranı) testlerinden elde edilen sonuçlar, her piyasada getirilerin tahmin edilebilir ve tahmin edilemez dönemler içerdiğini dolayısıyla sonuçların APH ile uyumlu olduğunu ortaya koymuştur. Doğrusal olmayan testlerden (Tsay, Mcleod-Li ve BDS) elde edilen bulgular her piyasada her alt dönem için getirilerin bağımlılık içerdiğini göstermiştir. Ghazani ve Araghi (2014) 1999-2013 dönemini kapsayan çalışmalarında günlük getirileri kullanarak İran'da TEPIX endeksinde Adaptif Piyasa Hipotezinin geçerliliğini araştırmışlardır. Doğrusal (otomatik varyans oranı ve otomatik portmanteau) ve doğrusal olmayan (genelleştirilmiş spektral ve McLeod-Li) testlerden elde edilen sonuçlar piyasada APH'nin geçerli olduğunu ortaya koymuştur. Urquhart ve McGroarty (2014) 1900-2013 dönemi için Dow Jones Industrial Average'da dört farklı takvim anomalisini dikkate alarak APH'nin geçerliliğini araştırmışlardır. Analizler sonucunda dört takvim anomalisinin APH'ni desteklediği sonucuna ulaşmışlardır. 
Hiremath ve Kumari (2014) Hindistan'da Sensex ve Nifty endekslerinde otokorelasyon, varyans oran, runs, McLeodLi, Tsay ve ARCH-LM testleri kullanarak APH'nin geçerliliğini analiz etmişlerdir. Doğrusal testler, Hindistan borsasının APH ile uyumlu bir şekilde bazı dönemlerde etkin bazı dönemlerde ise etkin olmadığını ortaya koymuştur. Buna karşılık, doğrusal olmayan testlerden elde edilen sonuçlar, son dönemde doğrusal olmayan bağımlılığın azaldığını göstermiştir. Noda (2016) Ekim 1961-Aralık 2015 dönemi için Japonya'da TOPIX ve TSE2 endekslerinde APH'nin geçerliliğini araştırmışlardır. Zamanla değişen (Time-varying) modelin kullanıldığı çalışmada TSE2'nin birçok dönemde TOPIX'e göre daha az etkin olduğu bulunmuştur. Ayrıca TOPIX piyasasının etkinliğinin değiştiği buna karşın TSE2'nin etkinliğinin değişmediğini ifade etmişlerdir.

Urquhart ve McGroarty (2016) Ocak 1990-Mayıs 2014 dönemi için çalışmalarında P500, FTSE100, NIKKEI225 ve EURO STOXX 50 endekslerinde hisse senedi getirilerinin önceden tahmin edilip edilemeyeceğini varyans oranı testi ile araştırmışlardır. Analizler sonucunda hisse senedi getirilerinin bazı dönemlerde tahmin edilebilir, bazı dönemlerde ise tahmin edilemez olduğu saptanmıştır. Hiremath ve Narayan (2016) Ocak 1991-Aralık 2013 dönemi Genelleştirilmiş Hurst testi kullanarak Hindistan borsasının (Sensex ve Nifty) etkinliğini incelemiş ve etkinlik ile finansal krizler, diğer uluslararası şoklar ve iç politika ve krizle ilgili önemli olaylar arasında pozitif bir ilişki olduğunu tespit etmişlerdir. Shahid ve Sattar (2017) günlük getiriler ile Ocak 1992-Aralık 2015 dönemini kapsayan çalışmalarında Pakistan hisse senedi piyasasında beş farklı takvim anomalisi ile APH'nin geçerliliğini araştırmışlardır. Sonuçlar beş farklı takvim anomalisinin zaman içerisinde değiştiğini ve dolayısıyla piyasada APH'nin geçerli olduğunu ortaya koymuştur. Rojas vd. (2017) Meksika'da birim ADF, Tsay, ARCH-LM ve BDS testleri ile APH'nin geçerliliğini 1994-2015 dönemi için incelemişlerdir. Yapılan analizler piyasanın bazı dönemlerde etkin olduğunu ortaya koymuştur. Khuntia ve Pattanayak (2018) APH'nin geçerliliğini Bitcoin piyasası için ele almışlardır. Bitcoin getirilerinde zamana göre değişen doğrusal ve doğrusal olmayan bağımlılı̆̆ı test etmişler ve sonuçlar piyasa etkinliğinin zamanla geliştiğini ve Bitcoin piyasasında APH'nin geçerliliğini ortaya koymuştur.

Gyamfi (2018) 4 Ocak 2011 ile 28 Ağustos 2015 dönemini kapsayan çalışmasında Gana Borsasında (GSEALSH ve GSEFSII indeksleri) APH'nin varlığını genelleştirilmiş spektral test, otomatik portmanteau Box-Pierce testi ve bootstrapped otomatik varyans oranı testi kullanarak incelemiştir. Yapılan analizler APH'nin her iki endekste de geçerli olduğunu ortaya koymuştur. Boya (2019) 1988-2018 dönemi için Fransa'da menkul kıymetler borsasının etkinlik derecesini varyans oranı testi ile incelemiştir. Yapılan analizler APH ile tutarlı bir şekilde piyasanın bazı dönemler etkin bazı dönemler ise etkin olmadığını ortaya koymuştur. Ayrıca çalışmada, etkin olmayan dönemlerin büyük makroekonomik olaylarla çakıştı̆ğ ifade edilmiştir. Shah ve Bahri (2019) 1 Temmuz 1997 - 28 Eylül 2018 dönemi için ABD (Dow Jones ve S\&P 500), Hong Kong (Hang Seng) ve Hindistan (BSE Sensex) borsalarında getirilerin öngörülebilirliğini Ljung-Box testi ve Chow-Denning testleri ile analiz etmişlerdir. Sonuçlar tüm endeksler ve tüm alt dönemler için getiri öngörülebilirliğinin APH ile uyumlu olduğunu göstermiştir.

Türkiye'de ise Ertaş ve Özkan (2018) ise 01.02.1988-01.02.2018 dönemini kapsayan çalışmalarında BIST 100 ile S\&P 500 Composite endekslerinin aylık getirileri kullanılarak söz konusu piyasalarda APH'nin geçerliliğini 60 aylık haddeleme yöntemi kullanarak analiz etmişlerdir. Sonuçlar APH'nin her iki ülke hisse senedi piyasasının davranışlarını açıklamada EPH'ye göre daha başarılı performans gösterdiğini ortaya koymuştur. Tablo 1'de literatürde yer alan çalışmalar özetlenmiştir.

Tablo 1. Literatür Özeti

\begin{tabular}{|l|c|l|c|}
\hline Yazar(lar) & Ülke(ler) & Yöntem & Sonuç \\
\hline Lim ve Brooks (2006) & 50 ülke & Hinich (1996) portmanteau çift korelasyon testi & APH geçerli \\
\hline Todea vd. (2009) & 6 Asya ülkesi & Hinich (1996) portmanteau çift korelasyon testi & APH geçerli \\
\hline Ito ve Sugiyama (2009) & ABD & zamanla değişen otokorelasyon & APH geçerli \\
\hline Kim vd. (2011) & ABD & $\begin{array}{l}\text { Varyans oranı, portmanteau ve genelleştirilmiş } \\
\text { spektral test }\end{array}$ & APH geçerli \\
\hline Smith (2012) & 18 ülke & Varyans oranı & APH geçerli \\
\hline Lim vd. (2013) & ABD & $\begin{array}{l}\text { Otomatik portmanteau Box-Pierce testi ve } \\
\text { bootstrapped otomatik varyans oranı testi }\end{array}$ & APH geçerli \\
\hline Popović vd. (2013) & Karabağ & Haddeleme analizi & APH geçerli \\
\hline Urquhart ve Hudson (2013) & 3 ülke & $\begin{array}{l}\text { otokorelasyon, runs ve varyans oran1, Tsay, } \\
\text { Mcleod-Li ve BDS }\end{array}$ & 3 testte değil \\
\hline Ghazani ve Araghi (2014) & İran & $\begin{array}{l}\text { Otomatik varyans oranı ve otomatik portmanteau, } \\
\text { spektral ve McLeod-Li }\end{array}$ & APH geçerli \\
\hline Urquhart ve McGroarty (2014) & ABD & Anomaliler kullanılmıştır & APH geçerli \\
\hline Hiremath ve Kumari (2014) & Hindistan & $\begin{array}{l}\text { Otokorelasyon, varyans oran, runs, McLeod-Li, } \\
\text { Tsay ve ARCH-LM }\end{array}$ & $\begin{array}{c}3 \text { testte APH geçerli } \\
3 \text { testte değil }\end{array}$ \\
\hline
\end{tabular}


Eyüboğlu, K., Eyüboğlu, S. / Journal of Yasar University, 2020, 15/59, 642-654

\begin{tabular}{|l|c|l|c|}
\hline Noda (2016) & Japonya & Zamanla değişen testler & $\begin{array}{c}\text { APH 1 endeks için } \\
\text { geçerli, } 1 \text { endeks için } \\
\text { geçerli değil }\end{array}$ \\
\hline Urquhart ve McGroarty (2016) & 4 ülke & Varyans oranı testi & APH geçerli \\
\hline Hiremath ve Narayan (2016) & 6 ülke & Genelleştirilmiş Hurst testi & APH geçerli \\
\hline Shahid ve Sattar (2017) & Pakistan & Anomaliler kullanılmıştır & APH geçerli \\
\hline Rojas vd. (2017) & Meksika & ADF, Tsay, ARCH-LM ve BDS & $\begin{array}{c}\text { APH geçerli (birçok } \\
\text { test için) }\end{array}$ \\
\hline Ertaş ve Özkan (2018) & Türkiye & Haddeleme yöntemi & APH geçerli \\
\hline Gyamfi (2018) & Gana & $\begin{array}{l}\text { Genelleştirilmiş spektral test, otomatik } \\
\text { portmanteau Box-Pierce testi ve bootstrapped } \\
\text { otomatik varyans oranı testi }\end{array}$ & $\begin{array}{c}\text { APH geçerli (birçok } \\
\text { test için) }\end{array}$ \\
\hline Boya (2019) & Fransa & varyansı oranı testi & APH geçerli \\
\hline Shah ve Bahri (2019) & 3 ülke & Ljung-Box testi ve Chow -Denning testleri & APH geçerli \\
\hline
\end{tabular}

\section{Veri Seti ve Yöntem}

Zayıf formda piyasa etkinliği, hisse senedi fiyatlarının rassal bir şekilde hareket ettiğini ve dolayısıyla gelecekteki fiyatları tahmin ederken geçmiş fiyatları analiz etmenin bir işe yaramayacağını ifade etmektedir. Bu çalışmada BIST-100 (XU100), BIST Sınai (XUSIN) ve BIST Mali (XUMAL) endekslerinde hisse senedi fiyatlarındaki geçmiş hareketlerin gelecekteki hareketleri tahmin etmek için kullanılıp kullanılamayacağı, diğer bir ifade ile hisse senedi hareketlerinin geçmişteki hareketlerden bağımsız olup olmadığını analiz etmek için çeşitli istatistiksel testler kullanılmıştır.

Eğer test istatistikleri, dönem boyunca getirilerin bağımlılığı ve bağımsızlığı arasında değişkenlik olduğunu gösteriyorsa, bu durum APH'nin söz konusu piyasalarda geçerli olduğunu gösterecektir. Piyasanın etkinliğinin gelişimini incelemek için tüm dönemin yanı sıra veri seti alt dönemlere ayrılmıştır. APH'nin geçerliliği hem doğrusal (otokorelasyon, runs ve varyans oranı) hem de doğrusal olmayan testler (Ljung-box, ARCH-LM ve BDS) ile incelenmiştir.

Çalışmada, 3 endeksin günlük kapanış fiyatları kullanılmıştır. Veriler tr.investing.com'dan elde edilmiştir. Veri aralığı XU100 için 02 Ocak 1990-17 Haziran 2019; XUSIN ve XUMAL için 02 Nisan 1991-17 Haziran 2019 arasındadır. Endekslerin günlük getirileri ise şu şekilde hesaplanmıştır.

$$
r_{t}=\ln \left(\frac{P}{P_{t-1}}\right)
$$

Burada $\mathrm{R}_{\mathrm{t}}$; endeksin $\mathrm{t}$ dönemi doğal logaritmik getirisini, $\mathrm{P}_{\mathrm{t}}$; endeksin $\mathrm{t}$ dönemindeki kapanış değerini ve $\mathrm{P}_{\mathrm{t}-1}$; ilgili endeksin t-1 dönemindeki kapanış değerini sembolize etmektedir.

\subsection{Doğrusal Testler}

\subsubsection{Otokorelasyon Testi}

Otokorelasyon testi, bir serideki rasgele değişkenlerin bağımsızlı̆̆ını araştırmak için basit ve güvenilir bir testtir. Otokorelasyonun bulunması, getirilerin bağımsız olmadığını gösterecektir. Seri korelasyonun ardışık değerlerinin sıfırdan farklı olup olmadığını değerlendirmeye yardımcı olur. $p_{\mathrm{k}}$ tüm otokorelasyon katsayılarının aynı anda sıfıra eşit olduğu hipotezini test etmek için Ljung ve Box'ın (1978) portmanteau Q istatistiklerini kullanılır. Test istatistiği şu şekilde hesaplanabilir (Hiremath ve Kumari, 2014: 3).

$$
L B=n(n+2) \sum_{k=1}^{m}\left(\frac{p_{k}^{2}}{n-k}\right)
$$

Burada n gözlem sayısını, m gecikme uzunluğunu göstermektedir. Test ki-kare $(\chi 2)$ dağılımını izlemektedir.

\subsubsection{Runs Testi}

Runs testi parametrik olmayan bir testtir. Bu test Hisse senedi getiri serisinin rassal olup olmadığının araştırılmasında kullanılabilmektedir. Bununla birlikte, otokorelasyon testinden farklı olarak, bu test için getirilerin normal dağılıma uygun olmasına gerek yoktur. Kesintisiz bir veri seti rassal ise, runs testinde, serideki fiili dizilimler, işaretlerden bağımsız olarak beklenen dizilimlere yakın olmalıdır.

Herhangi bir menkul kıymetin fiyatı bir günden diğerine artabilir (+), azalabilir (-) veya değişmeyebilir $(0)$. Bu şekilde oluşan "işaret” serisinde birbirini izleyen aynı işaretler bir "dizilim” olarak isimlendirilir. Yani bir dizilim, pozitif 
veya negatif getiri serisidir. Pozitif koşu sayısı P ile gösterilir, negatif koşular ise N ile gösterilir. Beklenen dizilimler (3) nolu formül yardımıyla hesaplanmaktadır (Urquhart ve Hudson, 2013: 131; Uyar ve Uzuner, 2015: 203).

$$
E(k)=\frac{2 P N(P+N)}{(P+N)}+1
$$

Koşuların varyansı ise şu şekilde hesaplanmaktadır;

$$
\sigma^{2}=\frac{2 P N(2 P N-P-N)}{(P+N)^{2}(P+N-1)}
$$

Eğer ki hesaplanan z-değeri kritik değerlerden büyükse, serinin bağımsız olduğunu ifade eden $\mathrm{H}_{0}$ hipotezi reddedilir.

\subsubsection{Varyans Oranı Testi}

Varyans oranı (VR) testi, hisse senedi getiri serilerinin ilişkili olup olmadığını değerlendirmek için kullanılan doğrusal testlerden biridir. İlk defa, bu test Lo ve Mackinlay (1988) tarafından geliştirilmiştir. Bu teste göre eğer getiriler rassal ise, $\mathrm{k}$ periyodunun varyansı herhangi bir periyoddaki varyansın k zamanına eşit olacaktır. $\mathrm{r}_{\mathrm{t}}{ }^{\prime} \mathrm{yi} \mathrm{t}$ zamanında bir varlık getirisi olarak kabul edersek, elde tutma süresi k olan varlık getirisi için VR;

$$
V R(k)=1+2 \sum_{j=1}^{k-1}\left(1-\frac{j}{k}\right) p_{j}
$$

şeklinde formüle edilecektir. Burada $\mathrm{p}_{\mathrm{j}}$, varlık getirisinin $\mathrm{j}$ seviyesindeki otokorelasyonudur. Varyans oranı testinin $\mathrm{H}_{0}$ hipotezi, tüm k'lar için VR = 1'dir. k elde tutma süresi seçimi tamamen isteğe bağlıdır ve herhangi bir istatistiksel gerekçe gösterilmeden yapılır (Ghazani ve Araghi, 2014: 53). Literatürde 2, 4, 8 ve 16 olarak elde tutma süreleri varyans oranının araştırılmasında dikkate alınmaktadır.

$\mathrm{Bu}$ çalışmada da aynı süreler dikkate alınmıştır. 1'den büyük olan VR(k) değerleri pozitif seri korelasyonu gösterirken 1'den küçük değerler negatif seri korelasyonları ifade etmektedir (Urquhart ve McGroarty, 2016: 41). Varyans oranının 1 olması durumunda ise, fiyatlar arasında korelasyon olmadığı ifade edilir.

\subsection{Doğrusal olmayan testler}

Yukarıda açıklanan testler borsa getirilerinde doğrusal bağımlılığın varlığını incelemektedir. Bu testler yalnızca doğrusal bağımlılı̆̆ı algılamaktadır. Ancak verilerde doğrusal olmayan bağımlılık da olabilmektedir. Çünkü doğrusal testlerden elde edilen bulgular ile doğrusal olmayan testlerden elde edilen bulgular farklı olabilmektedir. Genel olarak hisse senedi getirileri üzerine yapılan doğrusal testler bağımsızlığı gösterirken, doğrusal olmayan testler olası bağımlılığa dikkat çekmektedir (Alagidede, 2011; Urquhart ve Hudson, 2013).

Çalışmada doğrusal olmayan bağımlılığın varlığını araştırmak için bir dizi testler gerçekleştirilmiştir. Doğrusal olmayan testleri uygulamaya başlamadan önce AR(p) modelleri yardımıyla serilerdeki lineer bağımlılık ortadan kaldırılmıştır. Optimal gecikme uzunluğu, AR(p) modelinden elde edilen hata terimlerinin Ljung-Box (LB) Q istatistiğinin 20 gecikmeye kadar istatistiksel açıdan \%1'de anlamlı olmadığı gecikme uzunluğu olarak seçilmiştir. Bununla birlikte, Lim ve Hooy’un (2013) ifade ettiği gibi, genel olarak finansal getirilere doğrusal olmayan bağımlılığın büyük çoğunluğunun ARCH tipi bir model tarafından tespit edilecek koşullu değişen varyanstan kaynaklandığı kabul edilmektedir (Urquhart ve McGroarty, 2016: 42).

Bu nedenle kalıntılar için $\mathrm{H}_{0}$ ’ın reddedilmesi, getirilerde doğrusal olmayan bağımlılığın varlığını ve piyasanın etkin olmadığını gösterecektir. Önceden arındırılmış modelin kalıntıları, Ljung ve Box (1978), Engle (1982) ve Brock vd. (1996) tarafindan geliştirilen Ljung-box, ARCH-LM ve BDS doğrusal olmayan testler ile analizler gerçekleştirilmiştir.

\subsubsection{ARCH-LM Testi}

Engle (1982), ARCH dağılımını tespit etmek için Lagrange Çarpan testini önermiştir. Yardımcı bir regresyonun $\mathrm{R}^{2}$ sine dayanan test istatistiği,

$$
e_{t}^{2}=a_{0}+\sum_{i=1}^{p} a_{i} e_{t-i}^{2}+v_{t}
$$

Örneklem büyüklüğü n olduğunda, $\left\{\mathrm{e}_{\mathrm{t}}\right\}$ için bir lineer üretme mekanizmasının $\mathrm{H}_{0}$ hipotezi altında, bu regresyon için test istatistiği NR² asimptotik olarak dağılır (Hiremath ve Kumari, 2014: 3). 


\subsubsection{BDS Testi}

BDS testi, Brock vd. (1996) tarafından hisse senedi getirilerinde seri bağımlılık (veya doğrusal olmayan bir yapı) için popüler bir parametrik olmayan testtir. BDS testinde $\mathrm{H}_{0}$ hipotezi hata terimlerinin bağımsız benzer dağılıma sahip olduğunu ifade etmektedir. $\mathrm{H}_{0}$ '1n hipotezi reddedilmesi, serinin doğrusal olmayan öngörülebilirliğinin bir ölçüsü olmas1 nedeniyle piyasa etkinliğinin olmadığını göstermektedir. Test istatistiği şu şekilde hesaplanabilir: (Urquhart ve McGroarty, 2016: 42).

$$
W_{N}(e, T)=\left|C_{n}(e, T)-C_{1}(e, T)^{N}\right| x \sqrt{\frac{T}{S_{N}(e, T)}}
$$

BDS testi ile AR-GARCH filtreli getirilerin istatistiksel açıdan anlamlı bir bağımlılığa sahip olduğu tespit edilirse, hisse senedi getirilerinde doğrusal olmayan bir bağımlılık söz konusu olacak ve piyasanın etkin olmadığına karar verilecektir (Urquhart ve McGroarty, 2016: 42).

Çalışmada yer alan endekslerin değişen etkinliğini belirleyebilmek için Hiremath ve Kumari (2014)'nin çalışması dikkate alınarak tüm dönem 2 yıllık alt dönemlere ayrılmıştır. Alt dönemleri boyunca hisse senetlerinin davranışının zaman içinde getirilerin bağımlılığına/bağımsızlığına bağlı olarak beş şekilde hareket edebileceği öngörülmüştür. Bunlar; etkin, etkinliğe doğru ilerleyen, etkinlikten etkinsizliğe geçen, adaptif veya etkin olmayan şeklindedir.

Örneklem boyunca getirilerin bağımlılı̆̆ yok (fiyatlar tahmin edilemiyorsa) ise bu tür piyasalar etkindir. Bir piyasada, eğer getiriler bağımlı ancak zaman içinde getirilerdeki bağımlılık azalma eğiliminde ise piyasanın etkinleştiği ifade edilir. Getiriler, bağımlılığın en az üç farklı bağımlılık aşamasından geçtiyse (örneğin, bağımlı, bağımsız, bağımlı) piyasa adaptif olarak kabul edilir. Son olarak, örneklem boyunca getirilerin bağımsız olmadığı piyasalar (fiyatlar tahmin edilebiliyorsa) etkin olmayan piyasalar olarak adlandırılır (Urquhart ve Hudson, 2013: 131).

\section{Bulgular}

Endeks getirilerine ilişkin tanımlayıcı istatistikler Tablo 2'de raporlanmıştır. Buna göre her bir endeskin tüm dönemler için yatırımcılarına pozitif ortalama getiriler sağladığı görülmektedir. Standart sapma değerlerine göre ise en yüksek oynaklığın olduğu endeks tüm dönemler için BIST Mali iken, en düşük oynaklığa sahip endeks BIST Sınai endeksidir. Günlük getiriler her bir alt dönem için çoğunlukla negatif olarak çarpıktır. Bu durum aşırı negatif getirilerin büyüklüğünün aşırı pozitif getirilerden daha fazla olduğu anlamına gelmektedir. Getirilerin basıklığı ise birçok dönem için 3 'ten büyüktür. Bu durum dağılımın leptokurtik olduğunu göstermektedir. Ayrıca, her bir dönem için hesaplanan KolmogorovSmirnov (K-S) istatistiği dönemlerdeki günlük getirilerin normal dağılım göstermediğini ortaya koymaktadır.

Tablo 2. Endekslerin Günlük Getirilerine İlişkin Tanımlayıcı İstatistikler

\begin{tabular}{|c|c|c|c|c|c|c|c|c|c|}
\hline Dönem(ler) & $\begin{array}{c}\text { Gözlem } \\
\text { Sayıs }\end{array}$ & Ortalama & $\begin{array}{c}\text { Std. } \\
\text { Sapma }\end{array}$ & Maksimum & Minimum & Çarpıklık & Basıklık & $\begin{array}{c}\text { K-S Testi } \\
\text { p-değeri }\end{array}$ \\
\hline \multicolumn{7}{|c|}{ BIST 100 } \\
\hline Tüm dönem & 7445 & 0.00111 & 0.03962 & 0.60959 & -0.58920 & 0.62018 & 61.67897 & 0.000 \\
\hline $1990-1992$ & 831 & 0.00066 & 0.09714 & 0.60959 & -0.58920 & 0.39930 & 12.88678 & 0.000 \\
\hline $1993-1995$ & 751 & 0.00307 & 0.03020 & 0.09956 & -0.11100 & -0.30179 & 1.07341 & 0.000 \\
\hline $1996-1998$ & 747 & 0.00250 & 0.03161 & 0.15642 & -0.16167 & -0.30667 & 3.67915 & 0.000 \\
\hline $1999-2001$ & 730 & 0.00229 & 0.03721 & 0.17774 & -0.19979 & 0.10433 & 2.97852 & 0.000 \\
\hline $2002-2004$ & 747 & 0.00080 & 0.02407 & 0.11794 & -0.13341 & 0.05917 & 3.72868 & 0.000 \\
\hline $2005-2007$ & 756 & 0.00106 & 0.01726 & 0.06484 & -0.08671 & -0.35724 & 1.46838 & 0.000 \\
\hline $2008-2010$ & 753 & 0.00023 & 0.02078 & 0.12127 & -0.09014 & -0.01114 & 3.28967 & 0.004 \\
\hline $2011-2013$ & 757 & 0.00004 & 0.01592 & 0.06238 & -0.11064 & -0.75161 & 4.85699 & 0.000 \\
\hline $2014-2016$ & 755 & 0.00019 & 0.01335 & 0.05255 & -0.07348 & -0.32990 & 2.00074 & 0.003 \\
\hline $2017-2019$ & 618 & 0.00024 & 0.01250 & 0.04068 & -0.05839 & -0.33341 & 1.47458 & 0.000 \\
\hline \multicolumn{7}{|c|}{ BIST Sinai } \\
\hline Tüm dönem & 7099 & 0.00109 & 0.03909 & 0.50915 & -0.51187 & 2.17272 & 57.51871 & 0.000 \\
\hline $1991-1993$ & 733 & 0.00206 & 0.10368 & 0.50915 & -0.51187 & 1.13476 & 8.70075 & 0.000 \\
\hline $1994-1996$ & 750 & 0.00214 & 0.02888 & 0.09553 & -0.13320 & -0.36780 & 1.94944 & 0.000 \\
\hline $1997-1999$ & 736 & 0.00306 & 0.03146 & 0.14680 & -0.20537 & -0.71430 & 4.67366 & 0.000 \\
\hline $2000-2002$ & 746 & -0.00001 & 0.03191 & 0.18045 & -0.18014 & 0.20035 & 4.89481 & 0.000 \\
\hline $2003-2005$ & 749 & 0.00153 & 0.01701 & 0.10515 & -0.12199 & -0.59369 & 7.52068 & 0.000 \\
\hline $2006-2008$ & 753 & -0.00060 & 0.01779 & 0.08388 & -0.08619 & -0.63821 & 3.57930 & 0.000 \\
\hline $2009-2011$ & 755 & 0.00118 & 0.01382 & 0.06455 & -0.09622 & -0.95658 & 5.31573 & 0.000 \\
\hline $2012-2014$ & 755 & 0.00065 & 0.01203 & 0.06310 & -0.11401 & -1.37484 & 14.32676 & 0.000 \\
\hline $2015-2017$ & 757 & 0.00066 & 0.01095 & 0.03642 & -0.06176 & -0.54123 & 2.52432 & 0.000 \\
\hline $2018-2019$ & 365 & -0.00051 & 0.01273 & 0.03317 & -0.04389 & -0.47401 & 0.78534 & 0.094 \\
\hline \multicolumn{7}{|c|}{ BIST Mali } & & & \\
\hline
\end{tabular}


Eyüboğlu, K., Eyüboğlu, S. / Journal of Yasar University, 2020, 15/59, 642-654

\begin{tabular}{|c|c|c|c|c|c|c|c|c|}
\hline Tüm dönem & 7099 & 0.00110 & 0.04381 & 0.48628 & -0.44578 & 1.44952 & 33.32526 & 0.000 \\
\hline $1991-1993$ & 733 & 0.00203 & 0.11039 & 0.48628 & -0.44578 & 0.86841 & 5.49424 & 0.000 \\
\hline $1994-1996$ & 750 & 0.00217 & 0.03295 & 0.09347 & -0.12024 & -0.22647 & 0.77311 & 0.000 \\
\hline $1997-1999$ & 736 & 0.00427 & 0.03898 & 0.16061 & -0.22927 & -0.35741 & 3.38128 & 0.000 \\
\hline $2000-2002$ & 746 & -0.00066 & 0.03753 & 0.17455 & -0.20842 & 0.23183 & 3.11323 & 0.000 \\
\hline $2003-2005$ & 749 & 0.00211 & 0.02298 & 0.12241 & -0.14302 & -0.31288 & 5.41196 & 0.000 \\
\hline $2006-2008$ & 753 & -0.00067 & 0.02518 & 0.14122 & -0.10878 & 0.02004 & 2.86915 & 0.000 \\
\hline $2009-2011$ & 755 & 0.00083 & 0.01983 & 0.07686 & -0.07744 & -0.14511 & 1.28538 & 0.000 \\
\hline $2012-2014$ & 755 & 0.00064 & 0.01871 & 0.14896 & -0.12775 & -0.09487 & 10.00829 & 0.000 \\
\hline $2015-2017$ & 757 & 0.00022 & 0.01458 & 0.07135 & -0.08389 & -0.26076 & 2.72326 & 0.000 \\
\hline $2018-2019$ & 365 & -0.00078 & 0.01756 & 0.04846 & -0.07245 & -0.25539 & 1.14653 & 0.097 \\
\hline
\end{tabular}

Tablo 3'te hem tüm hem de alt dönemler için otokorelasyon, runs ve varyans oranı test sonuçları gösterilmiştir. Sonuçlar, üç endekste (BIST 100, BIST Sınai ve BIST Mali) tüm dönem için istatistiksel açıdan anlamlı otokorelasyon olduğunu ortaya koymaktadır. Buna göre bu endekslerde hisse senedi getirilerinin geçmiş fiyatlardan bağımsız olmadığı ifade edilebilir. BIST 100 için alt dönemler incelendiğinde ilk iki alt dönem için gecikmelerde istatistiksel açıdan anlamlı otokorelasyon olduğu görülmüştür. Bununla birlikte, 1996-1998, 2002-2004, 2005-2007, 2011-2013, 2014-2016 ve $2017-$ 2019 alt dönemlerinde otokorelasyon yoktur. Dolayısıyla zaman içinde getirilerdeki bağımlılık azalma eğiliminde olduğundan piyasanın etkinleştiği ifade edilebilir. 1999-2001 ve 2008-2010 dönemlerinde ise hisse senetlerinin geçmişteki hareketlerden bağımsız olmadığı tespit edilmiştir. Bu dönemler 2001 krizi ile 2008 finansal krizlerinin gerçekleşmiş olduğu dönemler ile örtüşmektedir. Bu bağlamda BIST-100 için krizlerin piyasanın etkinliğini azalttı̆̆ 1 şeklinde bir yorum yapılabilir.

BIST Sinai otokorelasyon sonuçlarına göre 1991-1993, 1997-1999, 2003-2005, 2015-2017 ve 2018-2019 dönemlerinde otokorelasyon ile karşılaşılmamıştır. Dolayısıyla bu dönemlerde piyasanın zayıf formda etkin olduğu, diğer bir ifade ile hareketlerin önceden tahmin edilemeyeceği söylenebilir. Aynı şekilde son iki alt dönemde getirilerin öngörülememesi piyasanın etkinleştiğini göstermektedir. 1994-1996, 2000-2002, 2006-2008, 2009-2011 ve 2012-2014 dönemlerinde ise getirilerin tahmin edilebildiği belirlenmiştir. Piyasanın etkin olmayan dönemlerinin bir kısmının 1994 ve 2001 Türkiye krizleri ile 2008 finansal kriziyle örtüşmektedir. Dolayısıyla piyasanın etkinlik derecesinin finansal piyasaları etkileyen olaylarla çakıştığı ifade edilebilir.

BIST Mali endeksi için otokorelasyon sonuçları incelendiğinde 1997-1999 dönemi hariç ilk 4 alt dönemde ve 20092011 döneminde hisse senedi fiyat hareketlerinin geçmiş dönemdeki hareketlere bağımlı olduğu görülmektedir. Dolayısıyla bu dönemlerde fiyatların tahmin edilebilir olduğu söylenebilir. 1997-1999, 2003-2008 ve 2012-2019 dönemlerinde ise piyasanın zayıf formda etkin olduğu tespit edilmiştir. Özellikle 2012 yılından sonra getirilerin geçmişteki hareketlerden bağımsız hale gelmesi piyasanın etkinleştiğini ortaya koymaktadır. Özetlemek gerekirse otokorelasyon testi sonuçları Borsa İstanbul endekslerinin çoğunlukla alt dönemler itibariyle etkin olmadığını ancak etkin olan dönemlerinde var olduğunu göstermektedir. Ayrıca, etkin olmayan dönemler genellikle dışsal olaylar ile ilişkilidir. Dolayısıyla sonuçlar APH'nin BIST-100, BIST Sınai ve BIST Mali endeks getirilerinin davranışlarını açıklamada EPH'ye göre daha başarılı olduğunu göstermektedir. Çünkü APH, piyasa koşullarına bağlı olarak etkinlik derecesinin zaman içinde değiştiğini ifade etmektedir.

Tablo 3. Endeksler için Doğrusal Test Sonuçları

\begin{tabular}{|c|c|c|c|c|c|c|c|c|}
\hline \multirow[b]{2}{*}{ Dönem(ler) } & \multicolumn{3}{|c|}{ Otokorelasyon } & \multirow{2}{*}{$\begin{array}{c}\text { Runs } \\
z- \\
\text { istatistiği }\end{array}$} & \multicolumn{4}{|c|}{ Varyans Orani testi } \\
\hline & $\begin{array}{c}1 \\
\text { gecikme }\end{array}$ & $\begin{array}{c}3 \\
\text { gecikme }\end{array}$ & $\begin{array}{c}5 \\
\text { gecikme }\end{array}$ & & $K=2$ & $K=4$ & $K=8$ & $K=16$ \\
\hline \multicolumn{9}{|c|}{ BIST 100 } \\
\hline Tüm dönem & $0.073^{\mathrm{a}}$ & $-0.012^{\mathrm{a}}$ & $-0.014^{\mathrm{a}}$ & $-1.795^{c}$ & $0.538^{\mathrm{a}}$ & $0.263^{\mathrm{a}}$ & $0.132^{\mathrm{a}}$ & $0.067^{\mathrm{a}}$ \\
\hline 1990-1992 & $0.173^{\mathrm{a}}$ & $-0.068^{a}$ & $0.045^{\mathrm{a}}$ & -1.493 & $0.705^{\mathrm{a}}$ & $0.321^{\mathrm{a}}$ & $0.168^{\mathrm{a}}$ & $0.086^{\mathrm{a}}$ \\
\hline $1993-1995$ & $0.199^{\mathrm{a}}$ & $0.046^{\mathrm{a}}$ & $0.001^{\mathrm{a}}$ & $-3.031^{a}$ & $0.629^{\mathrm{a}}$ & $0.308^{\mathrm{a}}$ & $0.162^{\mathrm{a}}$ & $0.085^{\mathrm{a}}$ \\
\hline 1996-1998 & 0.043 & -0.022 & -0.002 & -1.062 & $0.497^{\mathrm{a}}$ & $0.244^{\mathrm{a}}$ & $0.127^{\mathrm{a}}$ & $0.066^{\mathrm{a}}$ \\
\hline 1999-2001 & $0.970^{\mathrm{a}}$ & $0.949^{\mathrm{a}}$ & $0.936^{\mathrm{a}}$ & $-3.222^{\mathrm{a}}$ & $0.482^{\mathrm{a}}$ & $0.238^{\mathrm{a}}$ & $0.120^{\mathrm{a}}$ & $0.061^{\mathrm{a}}$ \\
\hline $2002-2004$ & 0.013 & -0.034 & -0.038 & 1.281 & $0.491^{\mathrm{a}}$ & $0.255^{\mathrm{a}}$ & $0.124^{\mathrm{a}}$ & $0.062^{\mathrm{a}}$ \\
\hline $2005-2007$ & 0.012 & -0.019 & -0.028 & 0.946 & $0.507^{\mathrm{a}}$ & $0.254^{\mathrm{a}}$ & $0.131^{\mathrm{a}}$ & $0.066^{\mathrm{a}}$ \\
\hline $2008-2010$ & $0.082^{\mathrm{b}}$ & $-0.063^{b}$ & 0.019 & $-1.795^{c}$ & $0.558^{\mathrm{a}}$ & $0.262^{\mathrm{a}}$ & $0.130^{\mathrm{a}}$ & $0.069^{\mathrm{a}}$ \\
\hline $2011-2013$ & -0.044 & 0.009 & $0.018^{c}$ & -1.418 & $0.445^{\mathrm{a}}$ & $0.265^{\mathrm{a}}$ & $0.117^{\mathrm{a}}$ & $0.058^{\mathrm{a}}$ \\
\hline 2014-2016 & -0.004 & 0.018 & -0.033 & $-2.586^{a}$ & $0.498^{\mathrm{a}}$ & $0.252^{\mathrm{a}}$ & $0.125^{\mathrm{a}}$ & $0.064^{\mathrm{a}}$ \\
\hline $2017-2019$ & 0.015 & 0.041 & -0.079 & 0.886 & $0.495^{\mathrm{a}}$ & $0.248^{\mathrm{a}}$ & $0.126^{\mathrm{a}}$ & $0.066^{\mathrm{a}}$ \\
\hline \multicolumn{9}{|c|}{ BIST Sinai } \\
\hline Tüm dönem & $-0.219^{a}$ & $-0.084^{a}$ & $-0.062^{\mathrm{a}}$ & $-2.552^{\mathrm{b}}$ & $0.432^{\mathrm{a}}$ & $0.208^{\mathrm{a}}$ & $0.109^{\mathrm{a}}$ & $0.053^{\mathrm{a}}$ \\
\hline 1991-1993 & -0.012 & -0.060 & -0.001 & -0.998 & $0.397^{\mathrm{a}}$ & $0.189^{\mathrm{a}}$ & $0.105^{\mathrm{a}}$ & $0.050^{\mathrm{a}}$ \\
\hline 1994-1996 & $0.191^{\mathrm{a}}$ & $-0.015^{\mathrm{a}}$ & $0.037^{\mathrm{a}}$ & -1.096 & $0.620^{\mathrm{a}}$ & $0.295^{\mathrm{a}}$ & $0.149^{\mathrm{a}}$ & $0.085^{\mathrm{a}}$ \\
\hline 1997-1999 & 0.042 & 0.017 & -0.055 & $-3.393^{a}$ & $0.494^{\mathrm{a}}$ & $0.247^{\mathrm{a}}$ & $0.129^{\mathrm{a}}$ & $0.069^{\mathrm{a}}$ \\
\hline $2000-2002$ & $-0.232^{a}$ & $-0.125^{a}$ & $-0.088^{a}$ & $-3.659^{a}$ & $0.493^{\mathrm{a}}$ & $0.237^{\mathrm{a}}$ & $0.114^{\mathrm{a}}$ & $0.057^{\mathrm{a}}$ \\
\hline $2003-2005$ & -0.036 & 0.037 & 0.077 & -1.280 & $0.486^{\mathrm{a}}$ & $0.245^{\mathrm{a}}$ & $0.121^{\mathrm{a}}$ & $0.062^{\mathrm{a}}$ \\
\hline $2006-2008$ & $0.103^{\mathrm{a}}$ & $-0.018^{b}$ & $0.002^{\mathrm{a}}$ & $-1.768^{c}$ & $0.558^{\mathrm{a}}$ & $0.283^{\mathrm{a}}$ & $0.140^{\mathrm{a}}$ & $0.067^{\mathrm{a}}$ \\
\hline
\end{tabular}


Eyüboğlu, K., Eyüboğlu, S. / Journal of Yasar University, 2020, 15/59, 642-654

\begin{tabular}{|c|c|c|c|c|c|c|c|c|}
\hline $2009-2011$ & $0.099^{\mathrm{a}}$ & $-0.039^{\mathrm{b}}$ & $-0.056^{\mathrm{c}}$ & -0.182 & $0.537^{\mathrm{a}}$ & $0.277^{\mathrm{a}}$ & $0.136^{\mathrm{a}}$ & $0.064^{\mathrm{a}}$ \\
\hline $2012-2014$ & $-0.086^{\mathrm{b}}$ & $0.067^{\mathrm{b}}$ & $0.078^{\mathrm{a}}$ & 0.036 & $0.432^{\mathrm{a}}$ & $0.255^{\mathrm{a}}$ & $0.115^{\mathrm{a}}$ & $0.057^{\mathrm{a}}$ \\
\hline $2015-2017$ & 0.030 & 0.022 & -0.087 & $-1.718^{\mathrm{c}}$ & $0.498^{\mathrm{a}}$ & $0.269^{\mathrm{a}}$ & $0.125^{\mathrm{a}}$ & $0.069^{\mathrm{a}}$ \\
\hline $2018-2019$ & 0.040 & -0.010 & -0.136 & 1.101 & $0.500^{\mathrm{a}}$ & $0.252^{\mathrm{a}}$ & $0.129^{\mathrm{a}}$ & $0.075^{\mathrm{a}}$ \\
\hline \multicolumn{7}{|c|}{ BIST Mali } \\
\hline Tüm dönem & $-0.057^{\mathrm{a}}$ & $-0.054^{\mathrm{a}}$ & $-0.072^{\mathrm{a}}$ & -0.107 & $0.473^{\mathrm{a}}$ & $0.251^{\mathrm{a}}$ & $0.119^{\mathrm{a}}$ & $0.057^{\mathrm{a}}$ \\
\hline $1991-1993$ & -0.063 & $-0.089^{\mathrm{b}}$ & $-0.114^{\mathrm{a}}$ & $-1.785^{\mathrm{c}}$ & $0.451^{\mathrm{a}}$ & $0.253^{\mathrm{a}}$ & $0.116^{\mathrm{a}}$ & $0.055^{\mathrm{a}}$ \\
\hline $1994-1996$ & $0.196^{\mathrm{a}}$ & $0.038^{\mathrm{a}}$ & $0.060^{\mathrm{a}}$ & -1.242 & $0.593^{\mathrm{a}}$ & $0.289^{\mathrm{a}}$ & $0.154^{\mathrm{a}}$ & $0.083^{\mathrm{a}}$ \\
\hline $1997-1999$ & 0.038 & -0.042 & -0.052 & -1.033 & $0.508^{\mathrm{a}}$ & $0.252^{\mathrm{a}}$ & $0.129^{\mathrm{a}}$ & $0.068^{\mathrm{a}}$ \\
\hline $2000-2002$ & $0.105^{\mathrm{a}}$ & $-0.099^{\mathrm{b}}$ & $-0.084^{\mathrm{b}}$ & $-3.513^{\mathrm{a}}$ & $0.485^{\mathrm{a}}$ & $0.239^{\mathrm{a}}$ & $0.119^{\mathrm{a}}$ & $0.059^{\mathrm{a}}$ \\
\hline $2003-2005$ & -0.018 & -0.007 & 0.041 & 1.060 & $0.498^{\mathrm{a}}$ & $0.255^{\mathrm{a}}$ & $0.130^{\mathrm{a}}$ & $0.064^{\mathrm{a}}$ \\
\hline $2006-2008$ & 0.049 & -0.013 & -0.019 & -0.620 & $0.525^{\mathrm{a}}$ & $0.254^{\mathrm{a}}$ & $0.125^{\mathrm{a}}$ & $0.068^{\mathrm{a}}$ \\
\hline $2009-2011$ & $-0.111^{\mathrm{a}}$ & $0.053^{\mathrm{a}}$ & $0.057^{\mathrm{a}}$ & -0.109 & $0.491^{\mathrm{a}}$ & $0.248^{\mathrm{a}}$ & $0.128^{\mathrm{a}}$ & $0.062^{\mathrm{a}}$ \\
\hline $2012-2014$ & 0.006 & -0.017 & 0.001 & 0.765 & $0.434^{\mathrm{a}}$ & $0.246^{\mathrm{a}}$ & $0.113^{\mathrm{a}}$ & $0.057^{\mathrm{a}}$ \\
\hline $2015-2017$ & -0.037 & 0.034 & -0.069 & $-1.782^{\mathrm{c}}$ & $0.486^{\mathrm{a}}$ & $0.240^{\mathrm{a}}$ & $0.119^{\mathrm{a}}$ & $0.063^{\mathrm{a}}$ \\
\hline $2018-2019$ & 0.031 & 0.071 & -0.081 & 1.206 & $0.539^{\mathrm{a}}$ & $0.268^{\mathrm{a}}$ & $0.139^{\mathrm{a}}$ & $0.067^{\mathrm{a}}$ \\
\hline
\end{tabular}

${ }^{\mathrm{a}},{ }^{\mathrm{b}} \mathrm{ve}{ }^{\mathrm{c}}$ sirasıyla $\% 1, \% 5$ ve $\% 10$ anlamlılık seviyesini göstermektedir.

Tablo 3'ün 5. sütununda runs testi sonuçları sunulmuştur. BIST 100 açısından tüm dönem ve 1993-1995, 1999-2001, 2008-2010, 2014-2016 alt dönemlerinde getirilerin rassal yürüyüş gösterdiğini savunan $\mathrm{H}_{0}$ hipotezi reddedilmiştir. 19901992, 1996-1998, 2002-2007, 2011-2013 ve 2017-2019 alt dönemlerinde ise getirilerin bağımsız olduğu görülmüştür. Diğer bir ifade ile getirilerin söz konusu dönemlerde öngörülemez olduğu belirlenmiştir.

BIST Sınai açısından tüm dönem ve 1997-1999, 2000-2002, 2006-2008 ve 2015-2017 alt dönemlerinde getiriler doğrusal açıdan bağımlıdır. Diğer dönemlerde ise getirilerin rassal olarak hareket ettiği tespit edilmiştir.

BIST Mali endekste ise tüm dönemlerde (1991-1993, 2000-2002 ve 2015-2017 hariç) getirilerin geçmişteki hareketler ile ilişkili olmadığı diğer bir ifade ile zayıf formda etkin olduğu belirlenmiştir.

Runs testi sonuçlarına göre BIST 100, BIST Sınai ve BIST mali endekslerinde piyasaların etkinliğinin zaman içerisinde değişebileceği görülmüştür. Dolayısıyla bu piyasalarda APH'nin geçerli olduğu söylenebilir. Ayrıca büyük makroekonomik olayların (1994 Krizi, 1999 Depremi, 2001 Krizi, 2008 Küresel Kriz ve 15 Temmuz darbe girişimi gibi) BIST 100, BIST Sınai ve BIST Mali endekslerinde etkin olmayan dönemlerini tanımlamak için uygun koşullar yaratmıştır. Genel olarak, sonuçlar APH ile tutarlıdır ve dahası etkinlik derecesi finansal piyasaları etkileyen olaylarla çakışmaktadır.

Varyans oranı sonuçları çalışmada yer alan Borsa İstanbul endekslerinde hem tüm dönem hem de alt dönemler itibariyle hisse senedi getirilerinin bağımlılı̆̆ını ve tahmin edilebilirliğini göstermektedir. Diğer bir ifade ile bu piyasaların zayıf formda etkin olmadığı saptanmıştır. Bu bulgu, EPH'nin Borsa İstanbul endeksleri için getirilerin davranışlarını açıklamada APH'ye göre daha başarılı olduğunu ortaya koymaktadır.

Otokorelasyon, runs ve varyans oranı gibi doğrusal testler getiri serilerinde doğrusal olmayan özellikleri ortaya çıkarmak için yeterli olmayabilir. Doğrusal bağımlılığı ret edememe, serinin bağımsızlığını kanıtlamak için yetersizdir (Hsieh, 1989).

Doğrusal olmama durumu, getirilerin öngörülebilirliği ve aşırı getiri potansiyelini ifade etmektedir. Doğrusal modellerin bu gibi koşullarda kullanılması, öngörülme açısından yanlış çıkarımların yapılmasına yol açabilir. Ayrıca, hisse senedi getirilerinde doğrusal olmamanın varlığı EPH ile çelişmektedir (Hiremath ve Kumari, 2014: 8).

$\mathrm{Bu}$ çalışmada, doğrusal olmayan bağımlılığın varlığını araştırmak için bir dizi doğrusal olmayan test kullanılmış ve sonuçları Tablo 4 ve Tablo 5'te verilmiştir. Tablo 4'te endekslere ilişskin Ljung-box ve ARCH-LM testlerinden elde edilen sonuçlar sunulmuştur. Doğrusallık için filtrelemeden sonra hesaplanan kalıntılar için LB istatistikleri, her bir Borsa İstanbul endeksinin alt örneği için \%1 anlamlılık seviyesinde 20 gecikmeye kadar otokorelasyon olmadığını göstermiştir.

Tablo 4. Endeksler için AR Etkisinden Arındırılmış Doğrusal Olmayan Test Sonuçları

\begin{tabular}{|c|c|c|c|c|c|c|c|c|}
\hline \multirow[b]{2}{*}{ Dönem(ler) } & \multirow[b]{2}{*}{ 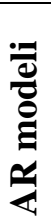 } & \multicolumn{4}{|c|}{ Ljung-box Test İstatistiği } & \multicolumn{3}{|c|}{ ARCH-LM Test İstatistiği } \\
\hline & & n & 을 & n & సి & N & 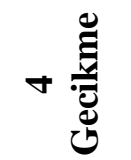 & ○ \\
\hline \multicolumn{9}{|c|}{ BIST 100 } \\
\hline Tüm dönem & 19 & 0.592 & 1.752 & 4.5252 & 7.929 & $752.938^{\mathrm{a}}$ & $710.890^{\mathrm{a}}$ & $733.087^{a}$ \\
\hline 1990-1992 & 1 & 6.520 & 10.047 & 12.532 & 15.053 & $22.889^{\mathrm{a}}$ & $18.529^{\mathrm{a}}$ & $29.804^{\mathrm{a}}$ \\
\hline 1993-1995 & 1 & 3.273 & 6.198 & 17.749 & 22.201 & $43.814^{\mathrm{a}}$ & $64.240^{\mathrm{a}}$ & $83.834^{\mathrm{a}}$ \\
\hline 1996-1998 & 8 & 0.227 & 2.003 & 12.800 & 20.212 & $74.239^{\mathrm{a}}$ & $75.097^{\mathrm{a}}$ & $97.566^{\mathrm{a}}$ \\
\hline $1999-2001$ & 0 & 4.775 & 9.667 & 15.453 & 19.095 & $98.277^{\mathrm{a}}$ & $102.473^{\mathrm{a}}$ & $107.405^{\mathrm{a}}$ \\
\hline $2002-2004$ & 0 & 3.112 & 12.356 & 16.461 & 20.081 & $28.539^{\mathrm{a}}$ & $29.718^{a}$ & $33.137^{\mathrm{a}}$ \\
\hline $2005-2007$ & 0 & 1.451 & 8.671 & 14.372 & 17.716 & $27.860^{\mathrm{a}}$ & $42.882^{\mathrm{a}}$ & $37.576^{\mathrm{a}}$ \\
\hline $2008-2010$ & 6 & 0.670 & 3.618 & 7.073 & 10.590 & $16.644^{\mathrm{a}}$ & $32.792^{\mathrm{a}}$ & $33.816^{\mathrm{a}}$ \\
\hline $2011-2013$ & 4 & 0.682 & 5.371 & 9.351 & 13.302 & $12.306^{\mathrm{a}}$ & $31.155^{\mathrm{a}}$ & $30.439^{\mathrm{a}}$ \\
\hline $2014-2016$ & 0 & 1.138 & 2.584 & 5.481 & 7.261 & $6.068^{\mathrm{b}}$ & $15.819^{\mathrm{a}}$ & $22.129^{a}$ \\
\hline $2017-2019$ & 0 & 5.943 & 10.116 & 13.988 & 22.367 & $7.146^{\mathrm{b}}$ & $15.051^{\mathrm{a}}$ & $21.284^{\mathrm{a}}$ \\
\hline
\end{tabular}


Eyüboğlu, K., Eyüboğlu, S. / Journal of Yasar University, 2020, 15/59, 642-654

\begin{tabular}{|c|c|c|c|c|c|c|c|c|}
\hline \multicolumn{9}{|c|}{ BIST Sinai } \\
\hline Tüm dönem & 20 & 0.040 & 0.572 & 1.648 & 2.394 & $266.206^{\mathrm{a}}$ & $369.724^{\mathrm{a}}$ & $426.587^{\mathrm{a}}$ \\
\hline 1991-1993 & 5 & 0.1631 & 4.6765 & 9.928 & $32.675^{\mathrm{b}}$ & $12.532^{\mathrm{a}}$ & $14.869^{\mathrm{a}}$ & $18.035^{\mathrm{a}}$ \\
\hline 1994-1996 & 1 & 3.924 & 6.580 & 15.875 & 23.726 & $49.242^{\mathrm{a}}$ & $73.750^{\mathrm{a}}$ & $101.882^{\mathrm{a}}$ \\
\hline $1997-1999$ & 5 & 0.022 & 3.629 & 8.448 & 11.492 & $21.927^{\mathrm{a}}$ & $23.292^{\mathrm{a}}$ & $28.694^{\mathrm{a}}$ \\
\hline $2000-2002$ & 0 & 3.625 & 12.569 & 16.975 & 21.946 & $199.007^{\mathrm{a}}$ & $206.624^{\mathrm{a}}$ & $215.006^{\mathrm{a}}$ \\
\hline $2003-2005$ & 6 & 0.285 & 5.979 & 13.754 & 20.245 & $59.239^{\mathrm{a}}$ & $60.221^{\mathrm{a}}$ & $62.008^{\mathrm{a}}$ \\
\hline 2006-2008 & 1 & 0.567 & 9.020 & 15.297 & 24.499 & $31.197^{\mathrm{a}}$ & $56.661^{\mathrm{a}}$ & $62.876^{\mathrm{a}}$ \\
\hline $2009-2011$ & 6 & 0.249 & 1.359 & 12.583 & 16.326 & $47.740^{\mathrm{a}}$ & $59.508^{\mathrm{a}}$ & $59.556^{\mathrm{a}}$ \\
\hline 2012-2014 & 9 & 0.104 & 0.463 & 7.530 & 11.873 & $12.342^{\mathrm{a}}$ & $29.363^{\mathrm{a}}$ & $29.742^{\mathrm{a}}$ \\
\hline $2015-2017$ & 0 & 8.932 & 16.294 & 21.422 & 25.073 & $7.810^{\mathrm{b}}$ & $22.216^{\mathrm{a}}$ & $32.330^{\mathrm{a}}$ \\
\hline 2018-2019 & 0 & 8.841 & 13.756 & 15.218 & 18.518 & $8.278^{b}$ & $11.490^{\mathrm{b}}$ & $11.559^{c}$ \\
\hline \multicolumn{9}{|c|}{ BIST Mali } \\
\hline Tüm dönem & 19 & 0.039 & 0.169 & 1.141 & 2.218 & $436.601^{\mathrm{a}}$ & $553.271^{\mathrm{a}}$ & $609.143^{\mathrm{a}}$ \\
\hline 1991-1993 & 5 & 2.336 & 6.676 & 14.313 & $20.986^{c}$ & $19.022^{\mathrm{a}}$ & $29.994^{\mathrm{a}}$ & $38.139^{\mathrm{a}}$ \\
\hline 1994-1996 & 1 & 4.265 & 8.578 & 17.309 & 20.742 & $83.913^{\mathrm{a}}$ & $105.910^{\mathrm{a}}$ & $124.114^{\mathrm{a}}$ \\
\hline 1997-1999 & 5 & 1.755 & 3.275 & 10.255 & 12.259 & $53.697^{\mathrm{a}}$ & $59.435^{\mathrm{a}}$ & $79.884^{\mathrm{a}}$ \\
\hline $2000-2002$ & 0 & 3.567 & 8.202 & 12.382 & 13.736 & $65.140^{\mathrm{a}}$ & $72.673^{\mathrm{a}}$ & $81.438^{\mathrm{a}}$ \\
\hline $2003-2005$ & 0 & 3.021 & 11.431 & 15.276 & 18.548 & $44.346^{\mathrm{a}}$ & $44.245^{\mathrm{a}}$ & $48.455^{\mathrm{a}}$ \\
\hline 2006-2008 & 11 & 1.856 & 2.190 & 3.213 & 5.719 & $5.306^{\mathrm{c}}$ & $31.852^{\mathrm{a}}$ & $32.552^{\mathrm{a}}$ \\
\hline 2009-2011 & 0 & 1.240 & 3.981 & 9.311 & 14.749 & $27.252^{\mathrm{a}}$ & $31.999^{\mathrm{a}}$ & $33.403^{\mathrm{a}}$ \\
\hline $2012-2014$ & 4 & 0.804 & 3.676 & 9.121 & 13.713 & $75.101^{\mathrm{a}}$ & $74.873^{\mathrm{a}}$ & $71.694^{\mathrm{a}}$ \\
\hline $2015-2017$ & 7 & 1.228 & 3.496 & 4.831 & 5.732 & 1.939 & $9.424^{c}$ & $14.697^{b}$ \\
\hline 2018-2019 & 0 & 5.443 & 9.706 & 11.915 & 20.400 & $7.202^{\mathrm{a}}$ & $9.384^{\mathrm{c}}$ & $10.690^{\mathrm{c}}$ \\
\hline
\end{tabular}

Ardından bu filtreli getiriler doğrusal olmayan bağımlılık analizi için ARCH-LM testine tabi tutulmuştur. Test sonuçları, her bir alt dönemin istatistiksel açıdan anlamlı doğrusal olmayan bir bağımlılığa sahip olduğunu göstermektedir. $\mathrm{Bu}$, her üç piyasanın da hem tüm dönem hem de alt dönemler boyunca etkin olmadığını ortaya koymuştur. Dolayısıyla bu piyasalarda, ARCH-LM testi sonuçlarına göre alım-satım kararını formüle etmek için geçmiş bilgiye ve teknik analize bağlı olarak aşırı getiri elde edebilen yatırımcıların olması beklenebilir.

Tablo 5'te endekslere ilişkin BDS testi sonuçları yer almaktadır. Buna göre AR filtrelemesinin uygulanmasından sonra, getirilerin istatistiksel açıdan anlamlı doğrusal olmayan özellik gösterdiği belirlenmiştir. Bu durum BIST 100, BIST Sınai ve BIST Mali endekslerinin her bir alt dönem ve tüm dönem için doğrusal olmayan bir şekilde etkin olmadığını göstermektedir.

Tablo 5. Endeksler için BDS testi sonuçları

\begin{tabular}{|c|c|c|c|c|c|c|c|c|c|c|c|c|c|}
\hline \multirow[b]{2}{*}{ Dönem(ler) } & \multirow{2}{*}{$\frac{:=}{\frac{0}{\sigma}}$} & \multicolumn{4}{|c|}{2} & \multicolumn{4}{|c|}{6} & \multicolumn{4}{|c|}{10} \\
\hline & & $\begin{array}{c}0.5 \\
\sigma\end{array}$ & $\begin{array}{l}\boldsymbol{1} \\
\sigma\end{array}$ & $\begin{array}{c}1.5 \\
\sigma\end{array}$ & $\begin{array}{l}2 \\
\sigma\end{array}$ & $\begin{array}{c}0.5 \\
\sigma\end{array}$ & $\begin{array}{l}\boldsymbol{1} \\
\boldsymbol{\sigma}\end{array}$ & $\begin{array}{c}1.5 \\
\sigma\end{array}$ & $\begin{array}{l}2 \\
\sigma\end{array}$ & $\begin{array}{c}0.5 \\
\sigma\end{array}$ & $\begin{array}{l}\mathbf{1} \\
\sigma\end{array}$ & $\begin{array}{c}1.5 \\
\sigma\end{array}$ & $\begin{array}{l}2 \\
\sigma\end{array}$ \\
\hline \multicolumn{13}{|c|}{ BIST 100} & \\
\hline Tüm & 19 & $0.013^{\mathrm{a}}$ & $0.026^{\mathrm{a}}$ & $0.024^{\mathrm{a}}$ & $0.016^{\mathrm{a}}$ & $0.004^{\mathrm{a}}$ & $0.058^{\mathrm{a}}$ & $0.112^{\mathrm{a}}$ & $0.106^{\mathrm{a}}$ & $0.000^{\mathrm{a}}$ & $0.034^{\mathrm{a}}$ & $0.127^{\mathrm{a}}$ & $0.164^{\mathrm{a}}$ \\
\hline 1990-1992 & 1 & $0.018^{\mathrm{a}}$ & $0.037^{\mathrm{a}}$ & $0.027^{\mathrm{a}}$ & $0.014^{\mathrm{a}}$ & $0.003^{\mathrm{a}}$ & $0.058^{\mathrm{a}}$ & $0.106^{\mathrm{a}}$ & $0.090^{\mathrm{a}}$ & $0.000^{\mathrm{a}}$ & $0.026^{\mathrm{a}}$ & $0.104^{\mathrm{a}}$ & $0.126^{\mathrm{a}}$ \\
\hline 1993-1995 & 1 & $0.006^{\mathrm{a}}$ & $0.016^{\mathrm{a}}$ & $0.016^{\mathrm{a}}$ & $0.010^{\mathrm{a}}$ & $0.001^{\mathrm{a}}$ & $0.026^{\mathrm{a}}$ & $0.066^{\mathrm{a}}$ & $0.072^{\mathrm{a}}$ & $0.000^{\mathrm{a}}$ & $0.008^{\mathrm{a}}$ & $0.054^{\mathrm{a}}$ & $0.096^{\mathrm{a}}$ \\
\hline 1996-1998 & 8 & $0.011^{\mathrm{a}}$ & $0.024^{\mathrm{a}}$ & $0.023^{\mathrm{a}}$ & $0.017^{\mathrm{a}}$ & $0.001^{\mathrm{a}}$ & $0.036^{\mathrm{a}}$ & $0.090^{\mathrm{a}}$ & $0.094^{\mathrm{a}}$ & $0.000^{\mathrm{a}}$ & $0.018^{\mathrm{a}}$ & $0.099^{\mathrm{a}}$ & $0.044^{\mathrm{a}}$ \\
\hline 1999-2001 & 0 & $0.005^{\mathrm{a}}$ & $0.013^{\mathrm{a}}$ & $0.017^{\mathrm{a}}$ & $0.014^{\mathrm{a}}$ & $0.001^{\mathrm{a}}$ & $0.019^{\mathrm{a}}$ & $0.048^{\mathrm{a}}$ & $0.060^{\mathrm{a}}$ & $0.000^{\mathrm{a}}$ & $0.007^{\mathrm{a}}$ & $0.041^{\mathrm{a}}$ & $0.075^{\mathrm{a}}$ \\
\hline $2002-2004$ & 0 & $0.003^{\mathrm{a}}$ & $0.009^{\mathrm{a}}$ & $0.010^{\mathrm{a}}$ & $0.007^{\mathrm{a}}$ & $0.000^{\mathrm{a}}$ & $0.015^{\mathrm{a}}$ & $0.044^{\mathrm{a}}$ & $0.051^{\mathrm{a}}$ & $0.000^{\mathrm{a}}$ & $0.005^{\mathrm{a}}$ & $0.045^{\mathrm{a}}$ & $0.081^{\mathrm{a}}$ \\
\hline $2005-2007$ & 0 & $0.004^{\mathrm{a}}$ & $0.012^{\mathrm{a}}$ & $0.012^{\mathrm{a}}$ & $0.008^{\mathrm{a}}$ & $0.000^{\mathrm{a}}$ & $0.013^{\mathrm{a}}$ & $0.043^{\mathrm{a}}$ & $0.054^{\mathrm{a}}$ & $0.000^{\mathrm{a}}$ & $0.003^{\mathrm{a}}$ & $0.033^{\mathrm{a}}$ & $0.073^{\mathrm{a}}$ \\
\hline $2008-2010$ & 6 & $0.006^{\mathrm{a}}$ & $0.010^{\mathrm{a}}$ & $0.009^{\mathrm{a}}$ & $0.008^{\mathrm{a}}$ & $0.002^{\mathrm{a}}$ & $0.033^{\mathrm{a}}$ & $0.076^{\mathrm{a}}$ & $0.082^{\mathrm{a}}$ & $0.000^{\mathrm{a}}$ & $0.013^{\mathrm{a}}$ & $0.074^{\mathrm{a}}$ & $0.123^{\mathrm{a}}$ \\
\hline 2011-2013 & 4 & $0.003^{\mathrm{a}}$ & $0.007^{\mathrm{b}}$ & $0.007^{\mathrm{b}}$ & $0.005^{\mathrm{a}}$ & $0.001^{\mathrm{a}}$ & $0.020^{\mathrm{a}}$ & $0.054^{\mathrm{a}}$ & $0.059^{\mathrm{a}}$ & $7.44 \mathrm{E}^{\mathrm{a}}$ & $0.008^{\mathrm{a}}$ & $0.057^{\mathrm{a}}$ & $0.098^{\mathrm{a}}$ \\
\hline 2014-2016 & 0 & -0.000 & $6.25 \mathrm{E}$ & -0.000 & -0.000 & 0.000 & 0.005 & $0.015^{\mathrm{b}}$ & $0.019^{\mathrm{a}}$ & $-6.1 \mathrm{E}$ & 0.001 & $0.012^{\mathrm{a}}$ & $0.022^{\mathrm{b}}$ \\
\hline $2017-2019$ & 0 & 0.001 & $0.006^{\mathrm{b}}$ & $0.006^{\mathrm{b}}$ & $0.005^{\mathrm{b}}$ & $0.000^{\mathrm{a}}$ & $0.009^{\mathrm{a}}$ & $0.023^{\mathrm{a}}$ & $0.020^{\mathrm{b}}$ & $2.86 \mathrm{E}^{\mathrm{a}}$ & $0.003^{\mathrm{a}}$ & $0.024^{\mathrm{a}}$ & $0.037^{\mathrm{a}}$ \\
\hline \multicolumn{13}{|c|}{ BIST Sınai } & \\
\hline Tüm & 20 & $0.036^{\mathrm{a}}$ & 0.04 & $0.029^{\mathrm{a}}$ & 0.019 & $0.039^{\mathrm{a}}$ & 0.160 & 0.16 & 0.13 & 0.01 & 0.16 & 0.24 & 0.217 \\
\hline 1991-1993 & 5 & $0.054^{\mathrm{a}}$ & 0.05 & $0.028^{\mathrm{a}}$ & 0.010 & $0.043^{\mathrm{a}}$ & 0.163 & 0.14 & 0.08 & 0.01 & 0.12 & 0.15 & 0.120 \\
\hline 1994-1996 & 1 & $0.009^{\mathrm{a}}$ & 0.02 & $0.021^{\mathrm{a}}$ & 0.011 & $0.001^{\mathrm{a}}$ & 0.040 & 0.09 & 0.09 & 6.34 & 0.01 & 0.08 & 0.140 \\
\hline 1997-1999 & 5 & $0.010^{\mathrm{a}}$ & 0.02 & $0.019^{\mathrm{a}}$ & 0.013 & $0.001^{\mathrm{a}}$ & 0.035 & 0.08 & 0.08 & 6.90 & 0.01 & 0.08 & 0.115 \\
\hline $2000-2002$ & 0 & $0.006^{\mathrm{a}}$ & 0.01 & $0.018^{\mathrm{a}}$ & 0.017 & $0.001^{\mathrm{a}}$ & 0.025 & 0.06 & 0.08 & 3.73 & 0.01 & 0.06 & 0.120 \\
\hline $2003-2005$ & 6 & $0.007^{\mathrm{a}}$ & 0.01 & $0.016^{\mathrm{a}}$ & 0.010 & $0.000^{\mathrm{a}}$ & 0.021 & 0.05 & 0.05 & 5.90 & 0.00 & 0.05 & 0.089 \\
\hline $2006-2008$ & 1 & $0.009^{\mathrm{a}}$ & 0.02 & $0.021^{\mathrm{a}}$ & 0.013 & $0.002^{\mathrm{a}}$ & 0.039 & 0.09 & 0.09 & 5.59 & 0.01 & 0.08 & 0.133 \\
\hline $2009-2011$ & 6 & $0.007^{\mathrm{a}}$ & 0.01 & $0.010^{\mathrm{a}}$ & 0.008 & $0.001^{\mathrm{a}}$ & 0.026 & 0.05 & 0.06 & 5.89 & 0.01 & 0.05 & 0.089 \\
\hline $2012-2014$ & 9 & $0.008^{\mathrm{a}}$ & 0.01 & $0.013^{\mathrm{a}}$ & 0.006 & $0.002^{\mathrm{a}}$ & 0.036 & 0.07 & 0.06 & 0.00 & 0.02 & 0.07 & 0.105 \\
\hline $2015-2017$ & 0 & 0.001 & 0.00 & $0.004^{\mathrm{c}}$ & 0.002 & 0.000 & 0.012 & 0.03 & 0.03 & 1.79 & 0.00 & 0.02 & 0.045 \\
\hline
\end{tabular}


Eyüboğlu, K., Eyüboğlu, S. / Journal of Yasar University, 2020, 15/59, 642-654

\begin{tabular}{|l|c|c|c|c|c|c|c|c|c|c|c|c|c|}
\hline $2018-2019$ & 0 & $0.004^{\mathrm{b}}$ & 0.00 & $0.010^{\mathrm{a}}$ & 0.008 & $-3.09 \mathrm{E}$ & 0.004 & 0.02 & 0.02 & $-4.4 \mathrm{E}^{\mathrm{b}}$ & 0.00 & 0.01 & 0.034 \\
\hline \multicolumn{10}{|c|}{ BIST Mali } \\
\hline Tüm & 19 & $0.020^{\mathrm{a}}$ & 0.03 & $0.026^{\mathrm{a}}$ & 0.018 & $0.014^{\mathrm{a}}$ & 0.109 & 0.13 & 0.11 & 0.00 & 0.09 & 0.19 & 0.193 \\
\hline $1991-1993$ & 5 & $0.053^{\mathrm{a}}$ & 0.04 & $0.025^{\mathrm{a}}$ & 0.009 & $0.054^{\mathrm{a}}$ & 0.180 & 0.16 & 0.09 & 0.01 & 0.14 & 0.17 & 0.121 \\
\hline $1994-1996$ & 1 & $0.011^{\mathrm{a}}$ & 0.02 & $0.024^{\mathrm{a}}$ & 0.014 & $0.001^{\mathrm{a}}$ & 0.034 & 0.08 & 0.09 & 0.00 & 0.01 & 0.07 & 0.126 \\
\hline $1997-1999$ & 5 & $0.010^{\mathrm{a}}$ & 0.01 & $0.021^{\mathrm{a}}$ & 0.016 & $0.002^{\mathrm{a}}$ & 0.029 & 0.06 & 0.06 & 0.00 & 0.01 & 0.06 & 0.097 \\
\hline $2000-2002$ & 0 & $0.004^{\mathrm{a}}$ & 0.01 & $0.012^{\mathrm{a}}$ & 0.009 & $0.000^{\mathrm{a}}$ & 0.018 & 0.04 & 0.06 & 6.07 & 0.00 & 0.04 & 0.085 \\
\hline $2003-2005$ & 0 & $0.004^{\mathrm{a}}$ & 0.01 & $0.012^{\mathrm{a}}$ & 0.009 & $0.000^{\mathrm{a}}$ & 0.015 & 0.04 & 0.04 & 1.23 & 0.00 & 0.04 & 0.075 \\
\hline $2006-2008$ & 11 & $0.003^{\mathrm{b}}$ & 0.00 & $0.009^{\mathrm{a}}$ & 0.006 & $0.001^{\mathrm{a}}$ & 0.022 & 0.06 & 0.07 & 8.19 & 0.00 & 0.06 & 0.109 \\
\hline $2009-2011$ & 0 & 0.001 & 0.00 & 0.004 & 0.003 & $0.000^{\mathrm{a}}$ & 0.012 & 0.03 & 0.03 & 2.95 & 0.00 & 0.02 & 0.059 \\
\hline $2012-2014$ & 4 & 0.001 & 0.00 & $0.005^{\mathrm{b}}$ & 0.004 & $0.000^{\mathrm{a}}$ & 0.013 & 0.04 & 0.04 & $-3.5 \mathrm{E}$ & 0.00 & 0.04 & 0.079 \\
\hline $2015-2017$ & 7 & 0.001 & 0.00 & 0.001 & 0.000 & $0.000^{\mathrm{a}}$ & 0.007 & 0.01 & 0.01 & 6.42 & 0.00 & 0.01 & 0.024 \\
\hline $2018-2019$ & 0 & $0.002^{\mathrm{c}}$ & 0.00 & $0.007^{\mathrm{c}}$ & 0.005 & 0.000 & 0.003 & 0.01 & 0.01 & 2.43 & 0.00 & 0.00 & 0.022 \\
\hline
\end{tabular}

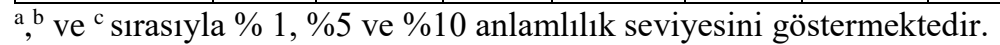

Tablo 6'da BIST 100, BIST Sınai ve BIST Mali endeksleri için iki yıllık sabit bir alt dönem büyüklüğünü dikkate alarak APH'nin geçerliliğine ilişkin yapılan testler sonucu elde edilen bulgular özetlenmiştir. Buna göre BIST 100, BIST Sınai ve BIST Mali endeksleri için otokorelasyon testi ve runs testi, getirilerin bağımsız ve bağımlı dönemler geçirdiğini ortaya koymuştur. Bu nedenle, bulgularımız, endekslerdeki getiri tahmininin zaman içinde APH ile tutarlı bir şekilde değiştiğini ve her bir piyasanın belirli piyasa koşullarına farklı bir şekilde adapte olduğunu göstermektedir.

Ancak, varyans oranı testi ve doğrusal olmayan ARCH-LM ve BDS testleri sonuçları her bir endeksin etkin olmadığını, diğer bir ifade ile getirin bağımlılık gösterdiğini ortaya koymaktadır. Bu sonuçlar, üç piyasanın doğrusal bağımlılığı konusunda somut sonuçlar alınamamasına rağmen, hem tüm hem de alt dönemler için güçlü bir doğrusal olmayan bağımlılık sergilediklerini göstermiştir.

Doğrusal bağımlılık testlerinin sonuçları uyarlanabilir ile uyumlu olsa da, doğrusal olmayan testler her endeks için güçlü bir bağımlılık olduğunu göstermektedir.

Tablo 6. Sonuç Özet Tablosu

\begin{tabular}{|c|c|c|c|c|c|}
\hline Dönem(ler) & $\begin{array}{c}\text { Otokorelasyon } \\
\text { testi }\end{array}$ & Runs testi & $\begin{array}{c}\text { Varyans Oranı } \\
\text { testi }\end{array}$ & $\begin{array}{c}\text { ARCH-LM } \\
\text { testi }\end{array}$ & BDS testi \\
\hline \multicolumn{6}{|c|}{ BIST 100 } \\
\hline Tüm dönem & Bağııllı & Bağımlı & Bağımlı & Bağımlı & Bağımlı \\
\hline 1990-1992 & Bağımlı & Băğmslz & Bağımlı & Bağımlı & Bağımlı \\
\hline 1993-1995 & Bağımlı & Bağımlı & Bağımlı & Bağımlı & Bağımlı \\
\hline 1996-1998 & Bă̆ımslz & Bă̆ımslz & Bağımlı & Bağımlı & Bağımlı \\
\hline 1999-2001 & Bağımlı & Bağımlı & Bağımlı & Bağımlı & Bağımlı \\
\hline $2002-2004$ & Bă̆gmsız & Bă̆ımsız & Bağımlı & Bağımlı & Bağımlı \\
\hline $2005-2007$ & Bă̆ımsız & Bă̆ımsız & Bağımlı & Bağımlı & Bağımlı \\
\hline $2008-2010$ & Bağımlı & Bağımlı & Bağımlı & Bağımlı & Bağımlı \\
\hline 2011-2013 & Bă̆ımsız & Bă̆ımsız & Bağımlı & Bağımlı & Bağımlı \\
\hline $2014-2016$ & Bă̆ımsız & Bağımlı & Bağımlı & Bağımlı & Bağımlı \\
\hline $2017-2019$ & Bă̆ımsız & Bă̆ımsız & Bağımlı & Bağımlı & Bağımlı \\
\hline Sonuç & Adaptif & Adaptif & Etkin değil & Etkin değil & Etkin değil \\
\hline \multicolumn{6}{|c|}{ BIST Sinai } \\
\hline Tüm dönem & Bağımlı & Bağımlı & Bağımlı & Bağımlı & Bağımlı \\
\hline 1991-1993 & Bă̆ımslz & Bă̆ımsız & Bağımlı & Bağımlı & Bağımlı \\
\hline 1994-1996 & Bağımlı & Bă̆ımslz & Bağımlı & Bağımlı & Bağımlı \\
\hline 1997-1999 & Bă̆ımslz & Bağımlı & Bağımlı & Bağımlı & Bağımlı \\
\hline $2000-2002$ & Bağımlı & Bağımlı & Bağımlı & Bağımlı & Bağımlı \\
\hline $2003-2005$ & Bă̆gmsız & Bă̆ımsız & Bağımlı & Bağımlı & Bağımlı \\
\hline $2006-2008$ & Bağımlı & Bağımlı & Bağımlı & Bağımlı & Bağımlı \\
\hline $2009-2011$ & Bağımlı & Bă̆ımsız & Bağımlı & Bağımlı & Bağımlı \\
\hline $2012-2014$ & Bağımlı & Bă̆ımsız & Bağımlı & Bağımlı & Bağımlı \\
\hline $2015-2017$ & Bă̆ımsız & Bağımlı & Bağımlı & Bağımlı & Bağımlı \\
\hline $2018-2019$ & Bă̆ımsız & Bă̆ımsız & Bağımlı & Bağımlı & Bağımlı \\
\hline Sonuç & Adaptif & Adaptif & Etkin değil & Etkin değil & Etkin değil \\
\hline \multicolumn{6}{|c|}{ BIST Mali } \\
\hline
\end{tabular}


Eyüboğlu, K., Eyüboğlu, S. / Journal of Yasar University, 2020, 15/59, 642-654

\begin{tabular}{|c|c|c|c|c|c|}
\hline Tüm dönem & Bağımlı & Bă̆ımslz & Bağımlı & Bağımlı & Bağımlı \\
\hline 1991-1993 & Bă̆ımsız & Bağımlı & Bağımlı & Bağımlı & Bağımlı \\
\hline 1994-1996 & Bağımlı & Bă̆gmslz & Bağımlı & Bağımlı & Bağımlı \\
\hline 1997-1999 & Bă̆ımsız & Bă̆ımsız & Bağımlı & Bağımlı & Bağımlı \\
\hline $2000-2002$ & Bağımlı & Bağımlı & Bağımlı & Bağımlı & Bağımlı \\
\hline $2003-2005$ & Bă̆gmsız & Bă̆ımsız & Bağımlı & Bağımlı & Bağımlı \\
\hline $2006-2008$ & Bă̆ımsız & Bă̆gmsız & Bağımlı & Bağımlı & Bağımlı \\
\hline $2009-2011$ & Bağımlı & Bă̆ımsız & Bağımlı & Bağımlı & Bağımlı \\
\hline $2012-2014$ & Bă̆ımsız & Bă̆ımsız & Bağımlı & Bağımlı & Bağımlı \\
\hline $2015-2017$ & Bă̆ımsız & Bağımlı & Bağımlı & Bağımlı & Bağımlı \\
\hline $2018-2019$ & Bă̆ımsız & Bă̆gmsız & Bağımlı & Bağımlı & Bağımlı \\
\hline Sonuç & Adaptif & Adaptif & Etkin değil & Etkin değil & Etkin değil \\
\hline
\end{tabular}

Doğrusal testlerin sonuçlarına göre, piyasalar genellikle etkin ve etkin olmayan dönemlerden geçmektedir. Doğrusal olmayan test sonuçlarına göre ise, endeksler etkin değildir ve bu etkin olmama durumu zamanla azalmamaktadır. Özet olarak, otokorelasyon ve runs testlerinden elde edilen sonuçlar APH'yi desteklerken, özellikle doğrusal olmayan testler piyasaların zayıf formda etkin olmadığını ortaya koymaktadır.

\section{Sonuç}

Bu çalışmada, Borsa İstanbul'da BIST 100, Sınai ve Mali endeksleri için günlük verileri kullanarak sözkonusu endekslerde APH'nin geçerli olup olmadığı incelenmiştir. Piyasa etkinliğinin zaman içerisindeki değişimlerini incelemek için hem doğrusal (otokorelasyon, runs ve varyans oranı) hem de doğrusal olmayan testlerden (Ljung-box, ARCH-LM ve BDS) yararlanılmıştır. Tüm bu testlerden elde edilen sonuçlar, piyasaların adaptif veya etkin olmadığına dair farklı bulgular ortaya koymuştur.

Buna göre doğrusal testlerden otokorelasyon ve runs testi sonuçları genel olarak piyasaların etkinliğinin APH ile tutarlı bir şekilde zaman içerisinde bazen etkin bazen ise etkin değil şeklinde gerçekleştiğini ortaya koymuştur. Elde edilen sonuçlar literatürde doğrusal testleri kullanan çalışmalar ile uyumludur (Kim vd. 2011; Alvarez-Ramirez vd. 2012, Urquhart ve Hudson, 2013; Hiremath ve Kumari, 2014) yani endeksler etkin ve etkin olmayan dönemler arasında geçiş yapmaktadır ve sonuç olarak APH'yi onaylamaktadır. Ayrıca çalışma makroekonomik olayların getirilerin tahmin edilebilirliği ile ilişkili olduğu varsayımını doğrulaması bakımından literatüre önemli katkı sağlamaktadır (Charles vd. 2012; Hiremath ve Narayan, 2016). Bu şoklar, küresel ve yurtiçi faktörler olarak tanımlanabilecek finansal, ekonomik veya politik olaylarla bağlantılıdır. Buna göre bu şoklar borsadaki etkinlik derecesinde bir bozulmaya neden olmakta ve piyasayı etkinsizliğe doğru sürüklemektedir. Dolayısıyla yatırımcılar bu dönemleri aşırı getiri elde etmek için kullanabilirler.

Ancak varyans oranı testi ile doğrusal olmayan testlerin sonuçları (ARCH-LM ve BDS testi) ise doğrusal ve doğrusal olmayan hisse senedi getirisi tahmin edilebilirliğinin zaman içinde değişmediğini ortaya koymuştur. Örneklem boyunca hisse senedi getirilerinde doğrusal olmayan bağımlılığın güçlü bir şekilde bulunduğuna dair bulgular, Borsa İstanbul endekslerinin hala etkin olmadığını göstermektedir. Bu sonuçlar doğrusal olmayan testler ile de analizlerini gerçekleştiren ve piyasaların etkin olmadığını vurgulayan Urquhart ve Hudson (2013) ve Hiremath ve Kumari (2014) bulguları ile örtüşmektedir.

Çalışmada yer alan endekslerde örneklem dönemi boyunca doğrusal olmayan özelliğe ilişkin güçlü kanıtlar tespit edilmiştir. Dolayısıyla doğrusal olamayan testlerin sonuçlarının dikkate alınmasının daha doğru olacağı düşünülmektedir. Buna göre endekslerde getiri hareketleri öngörülebilecek, diğer bir ifade ile aşırı getiriler elde edilebilecektir.

Sonuç olarak kullanılan yönteme göre değişmekle birlikte Borsa İstanbul endekslerinin tamamen öngörülebilir olmadığı sonucuna ulaşılmıştır. Getiriler için bazı testlerden elde edilen bulgular tahmin edilemeyen dönemler bulmakla birlikte, piyasanın zayıf formda etkin olmadığına yönelik de güçlü kanıtlar bulunmuştur. Borsa İstanbul endeks getirilerinin tahmin edilebilirliği ile ilgili gelecekteki çalışmalarda farklı testler ve farklı dönem uzunlukları kullanılarak endekslerin ADH'ye mi yoksa EPH'ye mi daha yakın olduğu araştırılabilir. 


\section{KAYNAKÇA}

Alagidede, Paul. 2011. "Return Behavior in Africa's Emerging Equity Markets." The Quarterly Review of Economics and Finance 51(2): 133-140.

Alvarez-Ramirez, Jose, Rodriguez, Eduardo \& Espinosa-Paredes, Gilberto 2012. "Is the US Stock Market Becoming Weakly Efficient Over Time? Evidence from 80-Year-Long Data.” Physica A: Statistical Mechanics and its Applications 391(22): 5643-5647.

Barber, Brad \& Odean, Terrance. 2001. "Boys will be Boys: Gender, Overconfidence, and Common Stock Investment." The Quarterly Journal of Economics 116(1): 261-292.

Boya, Christophe M. 2019. "From Efficient Markets to Adaptive Markets: Evidence from the French Stock Exchange." Research in International Business and Finance 49: 156-165.

Brock, William, Scheinkman, Jose A., Dechert, W. Davis, \& LeBaron, Blake. 1996. “A Test for Independence Based on the Correlation Dimension." Econometric Reviews 15(3): 197-235.

Charles, Amelie, Darné, Olivier, \& Kim, Jae H. 2012. "Exchange-rate Return Predictability and The Adaptive Markets Hypothesis: Evidence from Major Foreign Exchange Rates.” Journal of International Money and Finance 31(6): 1607-1626.

De Bondt, Werner F. \& Thaler, Richard. 1985. "Does the Stock Market Overreact?” The Journal of Finance 40: 793-805.

Engle, Robert F. 1982. "Autoregressive Conditional Heteroscedasticity with Estimates of the Variance of United Kingdom Inflation." Econometrica: Journal of the Econometric Society, 987-1007.

Ertaş, Fatih Coşkun \& Özkan, Oktay. 2018. "Piyasa Etkinliği Açısından Adaptif Piyasa Hipotezi’nin Test Edilmesi: Türkiye ve ABD Hisse Senedi Piyasaları Örneği." Finans Politik \& Ekonomik Yorumlar 55(642): 23-40.

Fama, Eugene F. 1970. "Efficient Capital Markets: A Review of Theory and Empirical Work." The Journal of Finance 25(2): 383-417.

Ghazani, Majid Mirzaee \& Araghi, Mansour Khalili. 2014. "Evaluation of the Adaptive Market Hypothesis as an Evolutionary Perspective on Market Efficiency: Evidence from the Tehran Stock Exchange." Research in International Business and Finance 32: 50-59.

Gyamfi, Emmanuel. Numapau. 2018. “Adaptive Market Hypothesis: Evidence from the Ghanaian Stock Market.” Journal of African Business 19(2): 195-209.

Hinich, Melvin J. 1996. "Testing for Dependence in the Input to a Linear Time Series Model." Journal of Nonparametric Statistics 6(2-3): 205-221.

Hiremath, Gourishankar S. \& Kumari, Jyoti. 2014. "Stock Returns Predictability and the Adaptive Market Hypothesis in Emerging Markets: Evidence from India.” SpringerPlus 3(1): 428.

Hiremath, Gourishankar S. \& Narayan, Seema. 2016. "Testing the Adaptive Market Hypothesis and Its Determinants for the Indian Stock Markets.” Finance Research Letters 19: 173-180.

Hsieh, David A. 1989. “Testing for Nonlinear Dependence in Daily Foreign Exchange Rates.” Journal of Business 62(3): 339-368.

https://tr.investing.com/indices/turkey-indices, Erişim tarihi 19.06.2019.

Ito, Mikio \& Sugiyama, Shunsuke. 2009. "Measuring the Degree of Time Varying Market Inefficiency." Economics Letters 103(1): 62-64.

Khuntia, Sashikanta \& Pattanayak, JK. 2018. "Adaptive Market Hypothesis and Evolving Predictability of Bitcoin.” Economics Letters 167: 26-28.

Lim, Kian-Ping \& Brooks, Robert. 2006. “The Evolving and Relative Efficiencies of Stock Markets: Empirical Evidence from Rolling Bicorrelation Tests Statistics.” SSRN Working Paper.

Lim, Kian-Ping \& Brooks, Robert. 2011. "The Evolution of Stock Market Efficiency Over Time: A Survey of the Empirical Literature.” Journal of Economic Surveys 25(1): 69-108.

Lim, Kian-Ping, Weiwei, Luo \& Kim, Jae H. 2013. “Are US Stock Index Returns Predictable? Evidence from Automatic Autocorrelation-Based Tests, Applied Economics 45(8): 953-962.

Lim, Kian-Ping \& Hooy, Chee-Wooi. 2013. "Non- Linear Predictability in G7 Stock Index Returns." The Manchester School 81(4): 620-637.

Ljung, Greta. M. \& Box, George E. 1978. “On a Measure of Lack of Fit in Time Series Models.” Biometrika 65(2): 297303.

Lo, Andrew W. 2004. “The Adaptive Markets Hypothesis.” The Journal of Portfolio Management 30(5): 15-29.

Lo, Andrew W. 2005. "Reconciling Efficient Markets with Behavioral Finance: The Adaptive Markets Hypothesis." Journal of Investment Consulting 7(2): 21-44.

Lo, Andrew W. \& MacKinlay, A. Craig. 1988. "Stock Market Prices do not Follow Random Walks: Evidence from a Simple Specification Test." The Review of Financial Studies 1(1): 41-66.

Noda, Akihiko. 2016. "A Test of the Adaptive Market Hypothesis Using A Time-Varying AR Model in Japan.” Finance Research Letters 17: 66-71.

Popović, Sasa, Mugoša, Ana \& Đurović, Andrija. 2013. “Adaptive Markets Hypothesis: Empirical Evidence from Montenegro Equity Market.” Ekonomska Istrazivanja - Economic Research 26(3): 31-46.

Rojas, Omar, Coronado, Semei \& Venegas-Martínez, Francisco. 2017. “Adaptive Market Hypothesis: Evidence from the Mexican Stock Exchange Index.” Journal of Applied Economic Sciences, 3(49): 688-697. 
Shah, Anand \& Bahri, Anu. 2019. "Are Stock Markets Adaptive? Evidence from US, Hong Kong and India. Evidence from US, Hong Kong and India.” SSRN papers, 1-36.

Shahid, Muhammed Naeem \& Sattar, Abdul. 2017. "Behavior of Calendar Anomalies, Market Conditions and Adaptive Market Hypothesis: Evidence from Pakistan Stock Exchange.” Pakistan Journal of Commerce and Social Sciences 11(2): 471-504.

Smith, Graham. 2012. "The Changing and Relative Efficiency of European Emerging Stock Markets.” The European Journal of Finance 18(8): 689-708.

Todea, Alexandru, Ulici, Maria \& Silaghi, Simona. 2009. “Adaptive Markets Hypothesis: Evidence from Asia-Pacific Financial Markets." The Review of Finance and Banking 1(1): 7-13.

Uyar, Aydın \& Uzuner, Mustafa. 2015. "Türkiye'de Altın Piyasasının Zayıf Formda Etkinliğinin Koşu Testi Uygulaması ile Sınanması.” Finansal Araştırmalar ve Çalışmalar Dergisi 7(12): 197-208.

Urquhart, Andrew \& Hudson, Robert. 2013. "Efficient or Adaptive Markets? Evidence from Major Stock Markets Using Very Long Run Historic Data." International Review of Financial Analysis 28: 130-142.

Urquhart, Andrew \& McGroarty, Frank. 2014. "Calendar Effects, Market Conditions and the Adaptive Market Hypothesis: Evidence from Long-Run U.S. Data." International Review of Financial Analysis 35: 154-166.

Urquhart, Andrew \& McGroarty, Frank. 2016. "Are Stock Markets Really Efficient? Evidence of the Adaptive Market Hypothesis." International Review of Financial Analysis 47: 39-49. 